Cahiers $d u$ MONDE RUSSE

\section{Cahiers du monde russe}

Russie - Empire russe - Union soviétique et États indépendants

\title{
La version roumaine du Synodikon de l'orthodoxie (Buzău, 1700) et les combats pour la « juste foi » à la fin du XVII ${ }^{\text {e }}$ siècle*
}

The Romanian version of the Synodikon of Orthodoxy (Buzău, 1700) and struggles for the "true faith" in the late seventeenth century

Ivan Biliarsky et Radu G. Păun

\section{CpenEdition}

Journals

Édition électronique

URL : http://journals.openedition.org/monderusse/10101

DOI : 10.4000/monderusse. 10101

ISSN : 1777-5388

Éditeur

Éditions de l'EHESS

Édition imprimée

Date de publication : 1 juillet 2017

Pagination : 395-434

ISBN : 978-2-7132-2697-7

ISSN : $1252-6576$

Référence électronique

Ivan Biliarsky et Radu G. Păun, « La version roumaine du Synodikon de l'orthodoxie (Buzău, 1700) et les combats pour la " juste foi » à la fin du xvile siècle* », Cahiers du monde russe [En ligne], 58/3 | 2017, mis en ligne le 01 juillet 2019, consulté le 06 janvier 2021. URL : http://journals.openedition.org/ monderusse/10101; DOI : https://doi.org/10.4000/monderusse.10101 


\section{LA VERSION ROUMAINE DU SYNODIKON DE L'ORTHODOXIE (BUZĂU, 1700) ET LES COMBATS POUR LA «JUSTE FOI » À LA FIN DU XVII SIĖCLE*}

L'été de l'an $1700^{1}$, les presses de l'Évêché de Buzău (Valachie) sortaient le Triôdion, qu'on appelle Trois odes. Imprimé maintenant pour la première fois sur l'ordre et aux frais du très illustre prince Iô Constantin Basarab Voïévode, métropolite du pays étant kyr Teodosie. Imprimé au saint-siège épiscopal de Buzău, en l'an de la Création du monde $7208^{2}$. Le Triôdion de Buzău est un livre bilingue : les offices sont tous en slavon d'Église, alors que la partie introductive, les rubriques et les lectures bibliques sont en roumain. Ce n'était pas du tout un cas isolé à cette époque-là, car le roumain, alors en plein essor, n'avait pas encore remplacé

\footnotetext{
* Cet article fait partie d'une recherche plus ample que nous comptons publier prochainement. L'espace imparti nous a contraints à réduire drastiquement les références bibliographiques ; elles seront complétées dans l'ouvrage en cours de préparation. Radu G. Păun tient à remercier ses collègues et amis Vera Tchentsova (Paris), Ovidiu Olar (Bucarest/Bochum), Lidia Cotovanu et Andrei Timotin (Bucarest) pour leurs suggestions et le matériel qu'ils lui ont aimablement fournis. Nous remercions également Vassa Kontouma (Paris) pour ses observations très précieuses et pour les articles qu'elle a eu l'obligeance de mettre à notre disposition.

1. La dédicace, signée par le métropolite Teodosie, est datée du mois de juin, mais il est probable que le livre est paru un peu plus tard, peut-être en juillet ou août, I. Bianu, N. Hodoș, Bibliografia românească veche, 1508-1830 [La bibliographie roumaine ancienne, 1508-1830], 1, Bucarest : Socec, 1903 [désormais $B R V, 1$ ], p. 409.

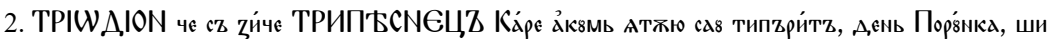

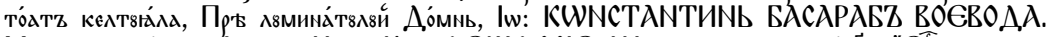

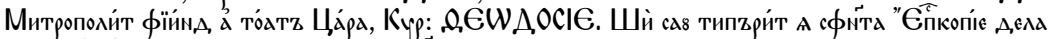

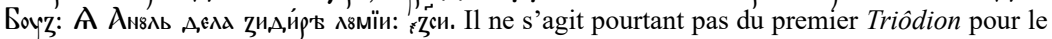
Carême imprimé en Valachie ; un autre avait été publié en 1578, mais de toute évidence, il était sorti des mémoires, Ibidem, p. 68-69 ; I. Bianu, D. Simonescu, Bibliografia românească veche, 1508-1830 [La bibliographie roumaine ancienne, 1508-1830], 4, Adăugiri şi îndreptări [Additions et corrections], Bucarest : Socec \& Co, 1944, p. 172.
} 
complètement le slavon ${ }^{3}$. Face aux difficultés soulevées par la traduction - depuis le slavon d'église et le grec - des textes sacrés, notamment de ceux à valeur dogmatique et performative, où le risque de tomber en hérésie à cause des mauvaises traductions était considérable, on a trouvé bon d'imprimer des livres bilingues (texte slavon ou grec et version roumaine en parallèle) ${ }^{4}$ ou bien de ne traduire en roumain que les rubriques et les lectures bibliques, afin que le peuple puisse comprendre la parole divine ${ }^{5}$. Mitrofan, fondateur de l'imprimerie de Buzău et maître typographe du lieu ${ }^{6}$, en avait fait son credo : sur les dix-sept livres qu'il a

3. Le slavon d'église a été la langue de la chancellerie et du culte en Valachie et en Moldavie pendant des siècles ; voir G. Nandriș, «Slavonic Culture in the Romanian Countries », Slavonic and East European Review, 24, 1946, p. 160-171 ; Gh. Mihăilă, « Apariția scrierii slave și pătrunderea ei la Nordul Dunării. Răspândirea în Țările Române a izvoarelor narative despre viața și activitatea fraților Constantin-Chiril și Metodie [L'apparition de l'écriture en slavon et sa diffusion au Nord du Danube. La diffusion dans les pays roumains des sources narratives sur la vie et l'activité des frères Constantin-Cyrille et Méthode] », in Idem, Contribuții la istoria culturii și literaturii române vechi [Contributions à l'histoire de la culture et de la littérature roumaines anciennes], Bucarest : Minerva, 1972, p. 9-78; P.P. Panaitescu, Inceputurile şi biruinţa scrisului în limba română [Les débuts et la victoire de l'écriture en langue roumaine], Bucarest : Academiei RSR, 1965. Sur les particularités du slavon d'église en Valachie et en Moldavie, voir L. Djamo-Diaconiță, Limba documentelor slavone emise în Țara Românească $\hat{\imath}$ secolele al XIV-lea-al XV-lea [La langue des documents slaves émis en Valachie et en Moldavie, XIV $-\mathrm{XV}^{\mathrm{e}}$ s.], Bucarest : Academiei RSR, 1971 ; P. Olteanu et al., Slava veche şi slavona românească [Le paléoslave et le slavo-roumain], Bucarest : Didactică şi Pedagogică, 1975 ; D.H. Mazilu, « Literatura română de expresie slavă [La littérature roumaine d'expression slave] », in Liturghierul lui Macarie 1508/2008 [Le Leiturgiarion de Macarie 1508/2008], Târgovişte : Arhiepiscopia Târgoviştei, 2008, p. 187-203.

4. Selon Șerban Greceanu, un des éditeurs de l'Évangile greco-roumain publiée à Bucarest, en 1693, il était souhaitable et fort utile de faire des éditions bilingues car, si jamais il y avait des erreurs de traduction ou des doutes sur le sens de tel ou tel passage, l'appel au texte original

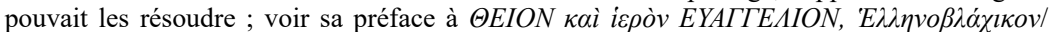
Sfânta şi dumnezăiasca EVANGHELIE, Elinească şi rumănească [Le saint et divin Évangile, grec et roumain], $B R V, 1$, p. 333.

5. Alors que pleinement conscient du risque de tomber en péché à cause de la méconnaissance des textes sacrés écrits en langues étrangères peu connues et peu pratiquées tant par les fidèles que par les prêtres eux-mêmes, le métropolite Teodosie dut avouer que le roumain était trop pauvre (littéralement « court ») pour tenter une traduction intégrale de la liturgie. C'est pourquoi il n'en traduisit que les rubriques ; voir sa préface à Svânta și dumnezăiasca Lyturghie [La sainte et divine Liturgie], Bucarest, 1680, BRV, 1, p. 230-237. Voir, en général, Panaitescu, Începuturile şi biruinţa; I. Gheție, Al. Mareș, Introducere în filologia românească [Introduction à la philologie roumaine], Bucarest : Enciclopedică română, 1974, p. 45-68 ; Idem, Originile scrisului în limba română [Les origines de l'écriture en langue roumaine], Bucarest : Ştiinţifică şi Enciclopedică, 1985 ; E. Munteanu, « Rolul Bisericii şi al textelor cu conţinut bisericesc în procesul de formare a vechii române literare. Un punct de vedere filologic [Le rôle de l'Église et des textes religieux dans le processus de formation du vieux roumain littéraire. Un point de vue philologique] ", in Şerban Cantacuzino, Antim Ivireanul şi Neofit Cretanul : promotori ai limbii române $\hat{\imath}$ cult [Şerban Cantacuzino, Antim Ivireanul et Neofit le Crétois : promoteurs de la langue roumaine dans le culte], Bucarest : Cuvântul Vieţii, 2013, p. 7-80.

6. Ancien évêque de Huși (en Moldavie) et futur évêque de Buzău (m. 1703) ; sur lui, voir N. Turcu, « Viaţa şi activitatea cultural-tipografică a Episcopului Mitrofan al Buzăului [La vie et l'activité culturelle et typographique de l'évêque Mitrofan de Buzău] », Biserica Ortodoxă Română, 83 (3-4), 1965, p. 280-296 ; D. Mihăescu, « Considerații asupra vieții și activității tipăritorului primei Biblii românești, Mitrofan, episcopul de Huși [Considérations sur la vie et l'activité du typographe de la première Bible roumaine, l'évêque Mitrofan de Huși] », Mitropolia Moldovei şi Sucevei, 55 (3-6), 1979, p. 314-224 ; C. Dima-Drăgan, « Un mare tipograf 
sûrement imprimés, neuf sont bilingues (slavon et roumain), quatre sont en roumain et quatre en $\operatorname{grec}^{7}$. C'est aussi le cas du Triôdion, imprimé sous le patronage du prince régnant Constantin Brâncoveanu (1688-1714) et sous la direction spirituelle du métropolite du pays, Teodosie (1668-1672;1679-1708) $)^{8}$.

Hormis le fait qu'il répondait à une nécessité pratique, le Triôdion de Buzău a ceci de particulier qu'il contient, en plus des services religieux à célébrer pendant le Carême, la seule version roumaine connue du Synodikon de l'Orthodoxie, pièce maîtresse de la lutte contre les hérésies dans le monde orthodoxe. Il convient par conséquent de s'interroger sur les raisons ayant conduit à la publication de ce texte.

\section{La tradition du Synodikon imprimé : éditions grecques et slaves}

La présence du Synodikon dans le Triôdion ne doit pas surprendre. Si à l'époque byzantine ce texte circulait surtout en livret séparé ${ }^{9}$, cette tradition connaît un changement important après la publication de la première édition du Triôdion grec par

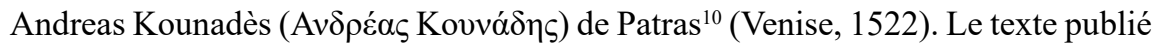

român din secolul al XVII-lea, Episcopul Mitrofan [Un grand typographe roumain du XVII ${ }^{\mathrm{e}} \mathrm{s}$., l'évêque Mitrofan] », Mitropolia Banatului, 32 (7-9), 1982, p. 457-467 ; D. Bădără, Tiparul românesc la sfârşitul secolului al XVII-lea și începutul secolului al XVIII-lea [L'imprimerie roumaine à la fin du XVII et au début du XVIII ${ }^{\mathrm{e}}$ s.], Brăila : Istros, 1998, p. 126-130.

7. Bădără, Tiparul românesc, p. 128-130.

8. Le livre s'ouvre par un court poème et une dédicace adressés au prince, la dernière étant signée par Teodosie lui-même, $B R V, 1$, p. 402-409. Malgré le nombre de travaux dédiés au règne de Brâncoveanu, aucune étude monographique sérieuse ne lui a été consacrée récemment ; voir, cependant, N. Iorga, Viața şi domnia lui Constantin-Vodă Brâncoveanu [La vie et le règne du prince Constantin Brâncoveanu], Vălenii de Munte : Neamul Românesc, 1914 ; Idem, Istoria românilor [Histoire des Roumains], 6, Monarhii [Les monarques], éd. par Șt. Andreescu, Bucarest : Enciclopedică, 2000², p. 313-379; Șt. Ionescu, P.I. Panait, Constantin vodă Brâncoveanu : viața - domnia - epoca [Le prince Constantin Brâncoveanu : la vie - le règne - l'époque], Bucarest : Științifică, 1969 ; Șt. Ionescu, Epoca brâncovenească : dimensiuni politice, finalitate culturală [L'époque de Brâncoveanu : dimension politique, finalité culturelle], Cluj-Napoca : Dacia, 1981.

9. J. Gouillard, « Le Synodikon de l'Orthodoxie : édition et commentaire », Travaux et mémoires, 2, 1967, p. 1-316, ici p. 6.

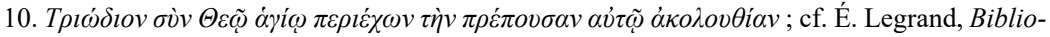
graphie hellénique ou description raisonnée des ouvrages publiés en grec par des Grecs aux $X V^{e}$ et $X V I^{e}$ siècles, 1, P. : Ernest Leroux, 1885, p. $173\left(\mathrm{n}^{\circ}\right.$ 66), et 3, P. : Maisonneuve, 1903, p. 273-274 ( $\left.\mathrm{n}^{\circ} 242\right)$; Gouillard, « Le Synodikon », p. 36. Kounadès est un des grands noms de l'imprimerie grecque de Venise, où il a voulu éditer une série complète d'œuvres liturgiques. Le projet a commencé en 1521 par la publication du Psautier; le Triôdion est le second et dernier livre sorti de sa typographie, car Kounadès mourut la même année. La typographie lui

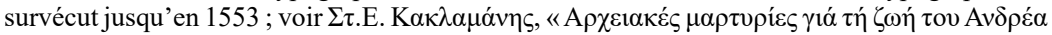

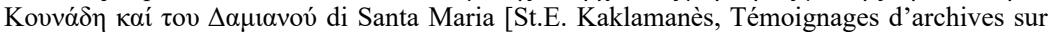

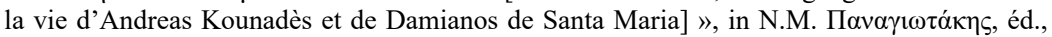

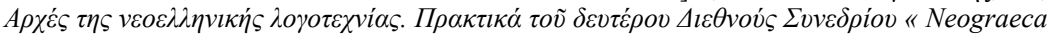

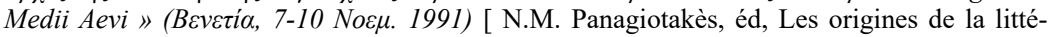
rature néo-hellénique. Actes du deuxième Congrès international « Neograeca Medii Aevi », Venise, les 7-10 novembre 1991], Venise : Istituto ellenico di studi bizantini e neoellenici, 1993, 2, p. 595-605. Les versions géorgienne, bulgare, serbe, russe et grecque du Synodikon 
par Kounadès représente la version $P$ (Paléologue) du Synodikon, selon la classification proposée par Jean Gouillard, liée à l'hésychasme et à la condamnation des antipalamites.

Cette particularité suscita les dures critiques de l'érudit grec uniate Léon Allatius (1586-1669), qui s'attaqua à ce qu'il considérait comme des égarements de doctrine présents dans le livre et notamment à « la matrice des erreurs », représentée, selon lui, par le Synodikon de l'Orthodoxie qui exaltait Grègorios Palamas (Г

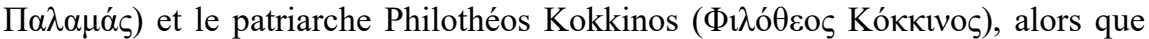
ceux-ci étaient, dans la vision d'Allatius et de l'Église de Rome, des hérétiques notoires ${ }^{11}$. Les critiques d'Allatius conduisirent à la réalisation d'une nouvelle édition du texte, considérablement revue et surtout épurée des traces des controverses théologiques du XIV ${ }^{\mathrm{e}}$ siècle. La responsabilité en fut assumée par Giovanni Francesco Barbarigo (ou Barbadico, 1658-1730), sous la direction spirituelle du pape Clément XI (Gianfrancesco Albani, pape de 1700 à 1721). Le livre qui en résulta (Bologne, 1724) ${ }^{12} \mathrm{~s}$ 'adressait en priorité aux Grecs unis à l'Église romaine et n'eut aucune influence sur la tradition imprimée du Triôdion et du Synodikon dans le monde orthodoxe, tradition qui suivit fidèlement l'édition de Kounadès.

Dans cet ouvrage et dans ses éditions ultérieures ${ }^{13}$, la mention dans le Synodikon de cinq métropolites de Patras (f. 83r), dont les pontificats couvrent tout le $\mathrm{XIV}^{\mathrm{e}}$ siècle $^{14}$, permet de localiser la version employée pour l'édition imprimée : il s'agit du Synodikon en usage au siège métropolitain de Patras. Comme l'indique Jean Gouillard, le dernier empereur à y être mentionné étant Jean Cantacuzène (m. 1383), elle peut être datée entre 1383 et $1391^{15}$. Il convient de souligner que cette version ne présente aucune autre particularité locale ; bien au contraire, tout

sont publiées en édition critique dans A. Melloni, éd., The Great Councils of the Orthodox Churches. Decisions and Synodika. From Constantinople 861 to Constantinople 1872, Turnhout : Brepols, 2016.

11. De libris et rebus ecclesiasticis Graecorum dissertationes duae et observationes variae, Parisiis, Sebastiani Cramoisy et Gabrieli Cramoisy, 1646, p. 143-193. Il traite du Triôdion aux p. 113-228. En plus, Allatius réédite le texte de la condamnation de Palamas par le patriarche Jean Kalékas (1344), Ibidem, p. 193-219. Sur Allatius, voir É. Legrand, Bibliographie hellénique ou description raisonnée des ouvrages publiés par des Grecs au dix-septième siècle, 3 , P. : Librairie des Archives nationales et de la Société de l'École des Chartes, 1895, p. 435-471; Th. Cerbu, Leone Allacci 1587-1669. The Fortunes of an Early Byzantinist, thèse de doctorat,

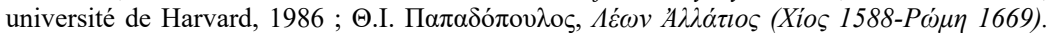
$\Sigma \dot{v} \mu \mu \iota \kappa \tau \alpha$ A $\lambda \lambda \alpha \tau \imath \alpha v \alpha ́$ [Th.I. Papadopoulos, Léon Allatius (Chios, 1588-Rome, 1669). Collectanea Allatiana], Athènes : Vivliophilia, 2007.

12. É. Legrand, Bibliographie hellénique ou description raisonnée des ouvrages publiés par des Grecs au dix-huitième siècle, 1, P. : Garnier, 1918, p. 198 ( $\left.{ }^{\circ} 162\right)$.

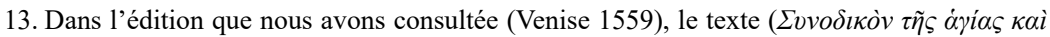

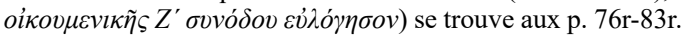

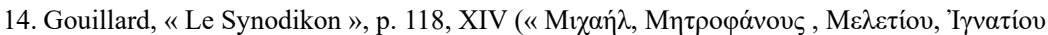

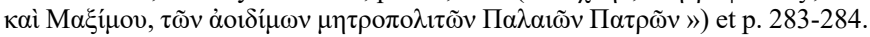

15. Ibidem, p. 32-33. 
laisse supposer que l'éditeur a voulu produire un texte qui gomme les différences régionales et s'adresse à tous les orthodoxes hellénophones ${ }^{16}$.

Alors que les premiers manuscrits slaves du texte sont assez anciens ${ }^{17}$, sa première édition imprimée ne parut qu'en 1627, dans le Triôdion de Pamvo Berynda (Па́мво Бери́нда), issu des presses du monastère des Grottes (Кисво-Печерська лавра) à Kiev ${ }^{18}$. La préface précise qu'il s'agit d'une traduction d'après le livre grec imprimé ${ }^{19}$. Plusieurs autres éditions ont été ensuite publiées à Kiev $(1640,1648)$ et à L'viv (deux en 1664, dont une reproduit l'édition de Kiev de 1640, et l'autre est publiée par la confraternité de l'église de la Dormition de la Vierge ; une troisième date de 1699) ${ }^{20}$. La seule édition du Synodikon publiée en Russie (Постная Tpiodb, M., 1656) ne contient pas de nouvelle traduction de l'original grec, mais suit fidèlement les éditions de Kiev et de L'viv, à quelques minimes différences lexicales et linguistiques près ${ }^{21}$.

Il nous reste à éclaircir les rapports entre les versions manuscrites du texte et celles imprimées ${ }^{22}$. Les versions serbes mises à part ${ }^{23}$, les trois copies manuscrites connues du Synodikon sud-slave (les manuscrits Palauzov et Drinov et le manuscrit slave 307 de la Bibliothèque de l'Académie roumaine ${ }^{24}$ ) forment un groupe individualisé, basé sur une seule et même traduction du texte grec. Il existe pourtant un certain rapprochement linguistique entre la copie bucarestoise et celle de Drinov, les seules qui contiennent la version $P$ du Synodikon. Il s'agit de l'existence, seulement dans ces deux copies, d'une forme composite désignant certains concepts théolo-

16. Alors que la tradition manuscrite contient nombre de synodika avec des particularités locales assez nettes ; voir les exemples fournis par Gouillard, « Le Synodikon ».

17. Е.В. Петухов, Очерки по литературной истории Синодика [E.V. Petuhov, Essais sur l'histoire littéraire du Synodikon], SPb. : Balaševa, 1895 ; В.В. Дергачев, « Вселенский синодик в древней и средневековой России [V.V. Dergačev, Le Synodikon œcuménique dans la Russie ancienne et médiévale] », Древняя Русь, n 3, 2001, p. 17-29 ; K.A. Maksimovič, « Synodicum Russicum », in Melloni, éd., The Great Councils, p. 497-505.

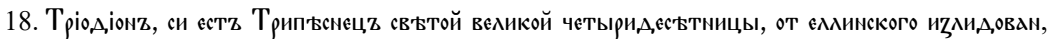
Петухов, Очерки, р. 61 ; Я. Запаско, Я. Ісаєвич. Пам'ятки книжскового мистецтва. Каталог стародруків виданих на Україні. Книга периа (1574-1700) [Ja. Zapasko, Ja. Isaevič, Monuments de l'art du livre. Catalogue des livres imprimés produits en Ukraine. Vol. 1, 1574-1700], L'viv : Višča škola, 1981, p. 45 (nº 160).

19. В. Мошин, « Сербская редакция Синодика (анализ текстов) [V. Mošin, La rédaction serbe du Synodikon (analyse des textes)] », Византийский Временник, 16, 1959, p. 317-394, ici p. 360.

20. Ibidem, p. 361.

21. Петухов, Очерки, p. 68-76 et 79; Мошин, « Сербская редакция », p. 360-361. Les Triôdia ultérieurs ne contiennent plus le Synodikon.

22. Nous avons utilisé l'édition de L'viv, 1664.

23. Sur les synodika serbes, voir Мошин, « Сербская редакция »; T. Subotin Golubovič, « Synodicum Serbicum », in Melloni, éd., The Great Councils, p. 470-496.

24. Voir И. Билярски, Палеологовият Синодик в славянски превод [I. Biljarski, Le Synodikon paléologue en traduction slave], Sofia : Université « St. Kliment Ohridski », 2013. 
giques importants ${ }^{25}$. Du point de vue lexical, ces formes sont assez étranges, car elles sont créées sur la base du préfixe grec ó o-$^{-}$, traduit en slavon par la particule въкоупо-, et non pas par $\mathfrak{k}_{,}$, ино-, comme il était d'usage. Les mots en question sont :

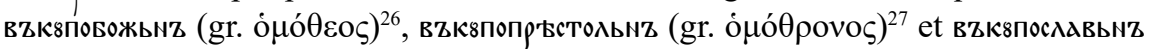

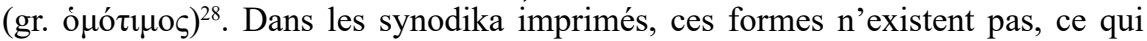
montre qu'il n'y a pas de relation directe entre les versions manuscrites citées et la version imprimée ${ }^{29}$.

Qui plus est, le Synodikon inséré dans le Triôdion de Kiev et dans les éditions ultérieures ne contient aucun ajout ou particularité locale, suivant ainsi l'édition grecque de Venise. Cette caractéristique distingue cette version des plus anciennes (Palauzov et Drinov), qui contiennent des ajouts et des particularités, tant dans les rubriques des éloges que dans celles des anathèmes ${ }^{30}$. Il en est de même dans le cas des rédactions serbes ${ }^{31}$ et des russes, où l'on trouve l'anathématisation des Judaïsants (juste après le chapitre contenant la condamnation de Barlaam et Akindynos), ainsi que nombre d'autres références locales (noms de métropolites, d'évêques et autres hauts prélats, de grands-ducs et de grandes-duchesses). Y ont également été ajoutés les noms de l'empereur Constantin XI Paléologue, de ceux morts lors de la conquête de Constantinople par les Ottomans, mais aussi des guerriers tombés pendant les campagnes de Kazan' (1548 et 1552); dans certains cas, la rubrique des commémorations est précédée par une description des événements ${ }^{32}$.

25. И. Билярски, М. Цибранска-Костова, « За един композитен тип и за Палеологовия вариант на славянския Синодик в Неделята на Православието » [I. Biljarski, M. Cibranska-Kostova, Sur un type lexical composite et la version paléologue du Synodikon du Dimanche de l'Orthodoxie en slavon] », Palaeobulgarica, 36 (1), 2012, p. 51-65.

26. BAR (Bibliothèque de l'Académie roumaine), ms. sl. 307, f. 13r, 14r ; М.Г. Попруженко, Синодик изаря Борила [M.G. Popruženko, Le Synodikon du tsar Boril], Sofia : D'ržavna pečatnica, 1928, p. 39 (ms. Drinov, f. 194v) ; ms. Palauzov f. 19r (є, иновжна) ; Gouillard, « Le Synodikon $»$, p. 77.

27. BAR, ms. sl. 307, f. 12v ; Попруженко, Синодик изаря Борила, p. 39 (Drinov, f. 194v) ; Gouillard, « Le Synodikon », p. 77.

28. BAR, ms. sl. 307, f. 12v ; Попруженко, Синодик ияаря Борила, p. 39 (Drinov, f. 194v) ;

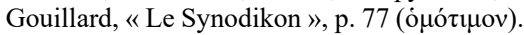

29. Petuhov n'exclut pas la possibilité que le traducteur en slavon ait connu la version représentée par le groupe Drinov, la copie de Bucarest y comprise, Очерки, p. 68-69; Попруженко, Синодик ияаря Борила, p. CXIII-CXVIII.

30. И. Божилов, А.-М. Тотоманова, И. Билярски, Борилов синодик. Издание и превод [I. Božilov, A.-M. Totomanova, I. Biljarski, Le Synodikon de Boril. Édition et traduction], Sofia : PAM, 2010, p. 149 et suiv.

31. В. Мошин, « Сербская редакция Синодика в Неделю Православия. Тексты [V. Mošin, La rédaction serbe du Synodikon pour le Dimanche de l'Orthodoxie. Textes] », Византийский Временник, 17, 1960, p. 278-353, iсi p. 302-304, 312-313, 319-320, 329-330, 337-340, 343-346, 348 ; Subotin Golubovič, « Synodicum Serbicum ».

32. Петухов, Очерки, p. 37-39 (f. 30v-31v) ; Дергачев, « Вселенский синодик» ; I. Biliarsky, «La solidarité entre les États dans le cadre de la communauté byzantine, vue dans l'optique des commémorations et des anathèmes du Synodikon du Dimanche de l'Orthodoxie », in B. Kasparian, éd., Les espaces de solidarité : la famille, l'État, l'Europe et le monde, Rennes : Presses universitaires de Rennes, 2015, p. 171-180, ici p. 177 ; Maksimovič, « Synodicum Russicum ». 
L'analyse comparative des textes imprimés grecs et slaves révèle aussi que la version slave du Synodikon contient une nouvelle traduction de l'original grec. Ainsi, dans le cas de la condamnation de Gérontios de Lampè (p. 177v), on lit dans

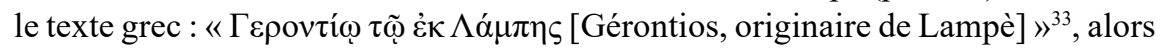

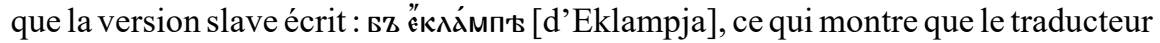
n'a pas compris l'original. Le deuxième exemple concerne le paragraphe reflétant les discussions autour des paroles de Jésus-Christ : « Mon Père est plus grand que moi » (p. 177v-178v). Ce paragraphe comprend les trois parties habituelles : l'introduction, la condamnation de l'ancien métropolite de Corfou, Constantin dit « le Bulgare », et les chapitres contre Iôannès Eirènikos ${ }^{34}$. Fait significatif, le traducteur appelle Iôannès Eirènikos, lша́nнь Mи́рномь [Ioan le Pacifique] (p. 178v), autrement dit, il traduit en slavon le nom du personnage, preuve d'un travail mécanique, non réfléchi. Il en va de même lorsqu'il est question des hérétiques notoires, en commençant par Arius et jusqu'à « tous les Eutychiens, Monothélites, Jacobites et

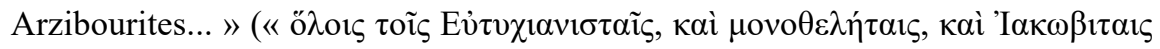

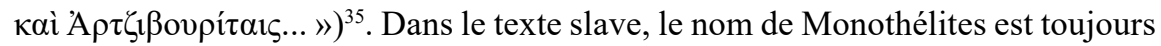
traduit (единоволии) et non pas employé comme terme technique, comme il était d'usage (p. 180r-180v). Enfin, le quatrième exemple concerne la mention des

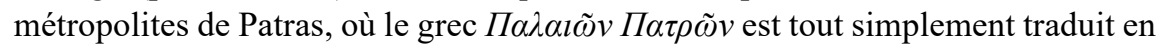

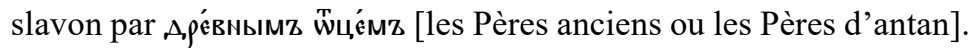

Tous ces exemples montrent que le Synodikon slave imprimé suit fidèlement le texte imprimé grec, alors que les erreurs de traduction indiquent qu'il s'agit d'une traduction nouvelle et non pas de la reproduction d'une traduction manuscrite plus ancienne.

\section{Le Synodikon roumain imprimé : contenu et origines}

À quelques exceptions près, le Synodikon roumain imprimé ne diffère pas de manière significative de l'original $\operatorname{grec}^{36}$ et doit être rangé sans hésitation aucune parmi les témoins de la version $P$ du texte. Cependant, a-t-il été traduit directement du grec ou bien d'après une des versions slaves, imprimées ou manuscrites ? En principe, les deux cas sont également possibles, surtout à l'extrême fin du $\mathrm{XVII}^{\mathrm{e}}$ siècle, alors que l'influence de la culture grecque va grandissant dans les deux

33. Gouillard, « Le Synodikon », p. 57 et 186-187.

34. Ibidem, p. 76-80.

35. Ibidem, p. 84 , note 299.

36. L'anathème nominal contre Iôannès Italos (Gouillard, « Le Synodikon », p. 57-61), est absent du texte roumain, tout comme de l'édition slave imprimée. De même, le Synodikon roumain ne contient pas l'éloge de Neilos (Kabasilas), qui est, en fait, un ajout tardif, Ibidem, p. $88-89$. 
principautés nord-danubiennes ${ }^{37}$, mais que la culture et la langue slaves n'ont pas complètement disparu non plus, surtout dans le domaine du livre religieux.

La préface du livre suggère qu'il s'agit d'une traduction du grec. En se référant à la langue source des textes roumains contenus dans le Triôdion, le métropolite Teodosie affirme : «ce qui se trouve là-dedans, [à savoir] les rubriques et les synaxaires et les lectures prophétiques, ont été traduits du grec dans la langue de notre pays $\gg{ }^{38}$. Le Synodikon était-il concerné par cette précision?

L'analyse comparative des textes nous conduit à une réponse négative. Il paraît beaucoup plus probable, en effet, que la traduction en roumain n'a pas été effectuée du grec, mais du slavon, à partir de l'un des synodika slaves imprimés. Notons d'abord que le texte de Buzău présente plusieurs traits communs avec celui du manuscrit $n^{\circ} 307$ de la Bibliothèque de l'Académie roumaine. Cela peut s'expliquer par la standardisation progressive des diverses variantes relevant de la version $P$ de l'original. Toutefois, les différences entre les deux textes sont encore plus importantes que leurs points communs et ne permettent pas d'établir que la traduction publiée à Buzău a été réalisée sur la base de ce manuscrit ${ }^{39}$. Quelques études de cas apporteront des arguments convaincants en faveur de cette interprétation.

Le premier concerne le paragraphe consacré à Gérontios de Lampè. Voici le texte grec :

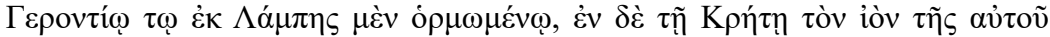

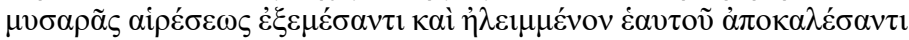

[Gérontios, originaire de Lampè, qui a craché en Crète le venin de son impure hérésie et s'est proclamé lui-même Oint] ${ }^{40}$.

37. Sur la culture hellénique dans les Principautés roumaines, voir D. Russo, « Elenizmul în România [L'hellénisme en Roumanie] », in Idem, Studii istorice greco-române. Opere postume, éd. par C.C. Giurescu et al., Bucarest : Fundația pentru Literatură și Artă " Regele Carol II », 1939, 2, p. 487-542 ; A.E. Karathanassis, « Des Grecs à la cour du Constantin Brâncoveanu,

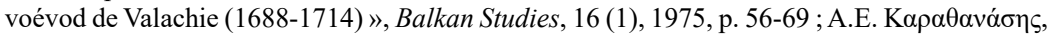

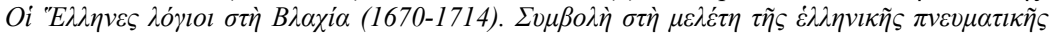

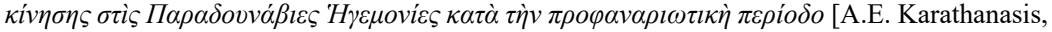
Les érudits grecs en Valachie. Contribution à l'étude du mouvement intellectuel hellénique dans les Principautés danubiennes pendant l'époque pré-phanariote], Thessalonique : Hidryma Meletōn Chersonēsou tou Haimou, 1982 ; A. Pippidi, Tradiţia politică bizantină în Ţările române în secolele XVI-XVIII [La tradition politique byzantine dans les Pays roumains aux $\mathrm{XVI}^{\mathrm{e}}$-XVIII ${ }^{\mathrm{e}}$ s.], Bucarest : Academiei RSR, 1983.

38. $B R V, 1$, p. 408 (« cele den-trânsa ale tipicului învățături și synaxarele și prooroceștile cetanii, den cea elinească spre a noastră cea de moșie limbă tălmăcindu »).

39. Ainsi, par exemple, certains éléments datés ou localisés dans le ms. slave 307 BAR (l'assemblée antihérétique du Mont Athos, les éloges pour les évêques de Hierissos), sont absents de la version imprimée ou bien sont remplacés par certains autres ; voir Biliarsky, « La solidarité », p. 176 ; Idem, « The Synodikon of Orthodoxy in B.A.R., Ms. sl. 307 and the Hagioretikon gramma of the Year 1344 », in V. Stanković, éd., The Balkans and the Byzantine World before and after the Captures of Constantinople, 1204 and 1453, Lanham, MD : Rowman \& Littlefield, 2016, p. 103-116.

40. Gouillard, « Le Synodikon », p. 57. 
Dans les manuscrits slaves, il a été traduit de manière assez exacte :

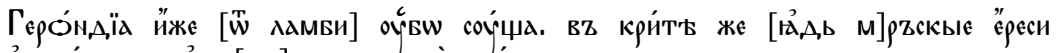

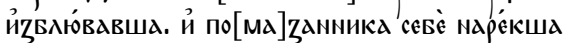

[Gérontios, [originaire] de Lambé, et qui cracha le poison de son hérésie odieuse en Crète et s'est proclamé lui-même Oint $[=$ Christ $]]^{41}$.

Le texte inséré dans le Triôdion de Kiev est différent et plus éloigné de l'original grec :

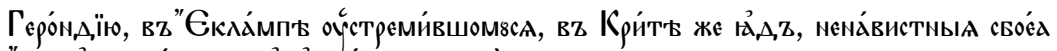

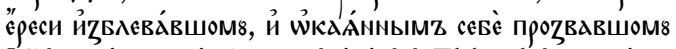

[Gérontios, qui s'est précipité à Eklambé et qui vomit le poison de son hérésie détestable et s'est proclamé misérable (p. 176v)].

Le texte roumain suit de très près cette dernière version :

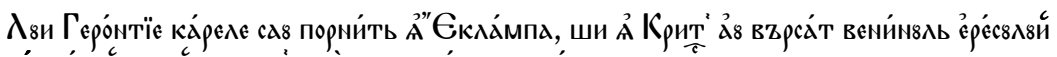

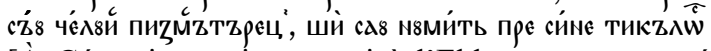

[À Gérontios, qui est parti à l'Eklampa, et a versé en Crète le venin de sa méchante hérésie et il s'est appellé lui-même misérable (p. 203)].

Cette comparaison indique que le texte roumain n'a pas été réalisé d'après les manuscrits slaves connus, mais sur la base du Triôdion slave imprimé.

Le deuxième argument est moins catégorique. Dans le paragraphe consacré à Iôannès Eirènikos le texte grec est le suivant :

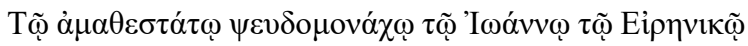

[Le très ignorant pseudo-moine et vain disputeur, Iôannès Eirènikos $]^{42}$.

Dans le manuscrit Drinov, cette partie n'existe plus aujourd'hui ; en revanche, elle se retrouve dans le manuscrit slave $\mathrm{n}^{\circ} 307$ de la Bibliothèque de l'Académie roumaine sous cette forme :

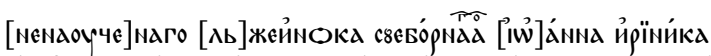

[le faux moine et ignorant, le vain combattant, Ioan Irinik $]^{43}$.

Dans le Synodikon imprimé à Kiev on lit :

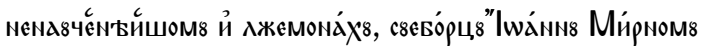

[le faux moine et le plus ignorant, le vain combattant Ioan le Pacifique (p. 178v)].

41. BAR ms. sl. 307, f. 10r ; Drinov, f. 191v ; Божилов, Тотоманова, Билярски, Борилов Синодик, p. 112.

42. Gouillard, « Le Synodikon », p. 81.

43. Божилов, Тотоманова, Билярски, Борилов синодик, p. 138. 
On observe aisément que le sobriquet de l'hérésiarque est tout simplement traduit

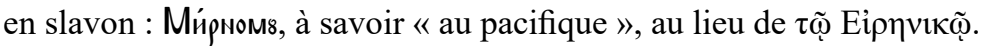

Dans le texte roumain, Iôannès Eirènikos est appelé seulement Ioan, sans plus :

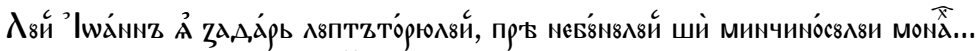
[à Ioan, au vain disputeur ${ }^{44}$, au très fou et mensonger moine].

Bien que le texte roumain ne suive pas fidèlement la version slave, comme dans l'exemple précédent, il s'éloigne aussi du texte grec, ce qui peut indiquer que la traduction roumaine n'a pas été réalisée à partir de l'original grec.

Le troisième argument, indirect également, concerne l'hérésie monothélite. Nous avons vu que pour désigner les Monothélites le traducteur en slavon a fait

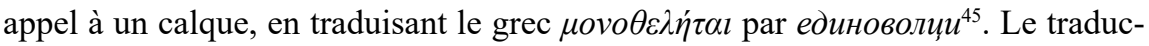
teur en roumain a omis de mentionner cette hérésie, une explication possible étant qu'il n'ait pas compris le mot en question.

Mais l'argument décisif, qui plaide pour une traduction d'après le Triôdion slave imprimé, est fourni par la partie mentionnant les métropolites de Patras, la seule qui comporte des différences régionales dans les synodika imprimés. Nous avons vu que l'auteur de l'édition slave n'a pas compris le texte, en traduisant П $\alpha \lambda \alpha \imath \tilde{\omega} v$ $\Pi \alpha \tau \rho \tilde{\omega} v$ par А,ре́внымz le texte suivant :

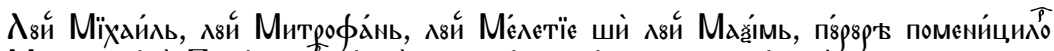

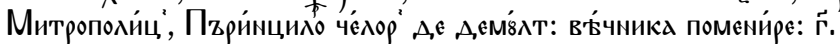

[à Mihail, à Mitrofan, à Meletie, à Ignatie et à Maxim, aux métropolites d'éternelle mémoire, les Pères d'antan, éternelle leur mémoire, 3 [fois]].

Dès lors, il nous semble évident que le Synodikon en roumain a été réalisé d'après la version slave, publiée d'abord à Kiev, en 1627, et rééditée ensuite à plusieurs reprises.

Au demeurant, il est logique qu'en l'absence de Triôdion imprimé, le service liturgique ait été assuré en Valachie (et en Moldavie aussi) grâce aux livres de culte provenant des terres ruthènes ${ }^{46}$, ce dont on est redevable pour beaucoup à Pierre

44. Plus exactement : « celui qui a combattu en vain ».

45. Cette appellation peut être trouvée dans certains textes russes des $\mathrm{XIII}^{\mathrm{e}}$ et $\mathrm{XIV}^{\mathrm{e}}$ siècles, Словарь древнерусского языка (XI-XIV вв.) [Dictionnaire du vieux russe, $\left.\mathrm{XI}^{\mathrm{e}}-\mathrm{XIV}^{\mathrm{e}} \mathrm{s}.\right], 3, \mathrm{M}$. : Рус. яз., 1990, p. 186.

46. Les rapports culturels des deux principautés avec les Slaves orientaux ne sont pas étudiés de manière satisfaisante. Voir, pour l'époque et les sujets qui intéressent ici, Șt. Ciobanu, « Din legăturile culturale româno-ucrainene. Ioanichie Galeatovschi și literatura românească veche [Sur les relations culturelles roumano-ukrainiennes. Ioanikij Galjatovskij et la littérature roumaine ancienne] ", Analele Academiei Române. Memoriile Secției Literare, $3^{\mathrm{e}}$ série, 8,1938 , p. 143-232 ; P.P. Panaitescu, Influența polonă și rusă în vechea cultură românească [L'influence polonaise et russe sur la culture roumaine ancienne], Bucarest : Université de Bucarest, 1935-1936 (cours dactylographié) ; V. Cândea, « L'humanisme d’Udriște Năsturel 
Moghila (roum. Petru Moghilă ou Movilă ; ukr. Петро Мохила ; pol. Piotr Mohyła, 1596-1646), issu de la famille régnante moldave, archimandrite du monastère des Grottes (1627), puis métropolite de Kiev (1632-1646) ${ }^{47}$. Du reste, la reprise de l'activité typographique en Valachie, sous le règne de Matei Basarab (1632-1654), et en Moldavie, au temps de Vasile Lupu (1634-1653), a été rendue possible grâce aux moyens techniques et au personnel fournis par Moghila, ce qui explique l'intense circulation des livres ruthènes dans les deux principautés et le fait qu'ils ont été souvent pris comme modèle pour les éditions locales ${ }^{48}$.

Les relations avec les Slaves orientaux ont connu un nouvel essor durant le pontificat du métropolite moldave Dosoftei (1671-1686, avec interruptions), qui a étudié à l'école de la confraternité orthodoxe de L'viv ${ }^{49}$. D'ailleurs, les premiers livres imprimés par Dosoftei ont vu le jour à Uhniv/Ugnev (rus. У́'Гнев; ukr. Угнів,

et l'agonie des lettres slavonnes en Valachie », Revue des Études Sud-Est Européennes 6 (2), 1968, p. 239-288 ; D.H. Mazilu, Literatura română barocă în context european [La littérature roumaine baroque en contexte européen], Bucarest : Minerva, 1996; Gh. Bezviconi, Contribuții la istoria relațiilor româno-ruse [Contributions à l'histoire des relations roumano-russes], Bucarest : Tritonic, 2004², p. 84-128.

47. Pour le nom du personnage, voir M. Cazacu, «Pierre Mohyla (Petru Movilă) et la Roumanie : Essai historique et bibliographique », Harvard Ukrainian Studies, 8 (1-2), 1984 [numéro thématique : The Kiev Mohyla Academy], p. 188-222, ici p. 188. De l'énorme bibliographie le concernant, voir les études publiées dans Harvard Ukrainian Studies 8 (1-2), 1984 ; A. Brüning, « Peter Mohyla’s Orthodox and Byzantine Heritage. Religion and Politics in the Kievan Church Reconsidered », in H.-J. Torke, éd., Von Moskau nach St. Petersburg. Das russische Reich im 17. Jahrhundert, Wiesbaden : Harrassowitz, 2000, p. 63-90 ; Idem, «"Voevodych zemli moldavskoi..." Peter Mohyla's Youth and Political Heritage », СОЦІУМ 4 (2004), p. 19-25. Sur les relations de Moghila avec les principautés roumaines, voir P.P. Panaitescu, « L'influence de l'œuvre de Pierre Mogila, archévêque de Kiev, dans les Principautés roumaines », Mélanges de l'École roumaine en France, 5 (1), 1926, p. 1-98 [= Petru Movilă. Studii [Petru Movilă. Études], éd. par Șt.S. Gorovei et M.-M. Székely, Bucarest : Enciclopedică, 1996, p. 9-76] ; Cazacu, « Pierre Mohyla ».

48. Panaitescu, « L’influence »; G. Ștrempel, « Sprijinul acordat de Rusia tiparului românesc în secolul al XVII-lea [L'aide accordée par la Russie à l'imprimerie roumaine au XVII ${ }^{\mathrm{e}} \mathrm{s}$.] », Studii și cercetări de bibliologie, 1, 1955, p. 19-27 ; Гр.И. Коляда, « Из истории книгопечатных связей России, Украины, Румыни в XVI-XVII вв. [Gr.I. Koljada, De 1'histoire des relations entre la Russie, l'Ukraine et la Roumanie dans le domaine du livre imprimé, $\mathrm{XVI}^{\mathrm{e}}-\mathrm{XVII}^{\mathrm{e}} \mathrm{s}$.] », in M.Н. Тихомиров et al., éds., У истоков русского книгопечатания [M.N. Tihomirov, Des origines de la typographie russe], M. : Izd. Akademij nauk SSSR, 1959, p. 81-100 ; Cândea, "L'humanisme »; O. Yurchyshyn-Smith, " The Printing-House of the Monastery of Trei Ierarhi in Iași and its Staff », Восточноевропейский Археологический Журнал, 3 (10), 2001, (http://archaeology.kiev.ua/journal/030501/yurchyshyn.htm).

49. Sur Dosoftei, voir Șt. Ciobanu, Dosoftei, Mitropolitul Moldovei şi activitatea lui literară. Contribuţii la istoria literaturii româneşti şi a legăturilor româno-ruse literare din secolul al XVII-lea [Dosoftei, le métropolite de la Moldavie et son activité littéraire. Contributions à l'histoire de la littérature roumaine et des relations littéraires roumano-russes au XVII ${ }^{\mathrm{e}} \mathrm{s}$.], trad. du russe par Șt. Berechet, Iași, s.n., 1918 ; R[odica] Ș[uiu], « Dosoftei, mitropolitul [Dosoftei, métropolite] ", in Dicționarul literaturii române de la origini până la 1900 [Le dictionnaire de la littérature roumaine des origines à 1900], Bucarest : Academiei RSR, 1979, p. 296-302 (avec bibliographie); D.H. Mazilu, Introducere în opera lui Dosoftei [Introduction à l'œuvre de Dosoftei], Bucarest : Minerva, 1997 ; N.A. Ursu, N. Dascălu, Mărturii documentare privitoare la viaţa şi activitatea Mitropolitului Dosoftei [Témoignages concernant la vie et l'activité du métropolite Dosoftei], Iași : Trinitas, 2003. 
dans la région de $\mathrm{L}^{\prime}$ viv) ${ }^{50}$, en 1673 , alors que le matériel nécessaire pour la typographie qu'il a fondée en Moldavie a été fourni par le patriarche de Moscou, Ioahim (Иоахим $)^{51}$. Il convient de noter, à ce point, qu'un des collaborateurs de Dosoftei a été précisément Mitrofan, l'éditeur du Triôdion de $1700^{52}$. En même temps, dans la Valachie de Constantin Brâncoveanu, les modèles ruthènes et russes sont souvent préférés aux grecs, à la fois pour les traductions en roumain des livres liturgiques qu'en tant que source d'inspiration des programmes iconographiques des églises et des monastères. Des livres produits à Kiev et L'viv sont très présents en Valachie (et en Moldavie aussi), certains commandés par le prince lui-même, alors que d'autres y sont arrivés sous forme de dons reçus par les pèlerins ${ }^{53}$. Parmi eux, on retrouve plusieurs éditions du Triôdion pour le Carême (Tріодь nїсна) : Kiev, 1640 et 1648 ; L'viv, 1664 et 1699, et du Triôdion-Pentèkostarion (Tpiodь цвітна) : Kiev, 1631 ; L'viv, 1642, 1663 et $1679^{54}$. L'édition de 1631 est dédicacée par Pierre Moghila à son frère Moise, prince régnant de la Moldavie ${ }^{55}$, alors que la suivante (L'viv, 1642) a connu plusieurs tirages, dédicacés par le typographe Mihail Sl'ozka (Михаил Сльозка), respectivement au prince Matei Basarab, qui aurait financé la publication du livre, à Vasile Lupu et à Pierre Moghila lui-même ${ }^{56}$. À l'époque qui

50. Il s'agit de Psaltirea în versuri [Psautier en vers] et d'Acatistul Maicii Domnului [Acathiste de la Mère de Dieu], tous les deux en roumain, BRV, 1, p. 209-214 et 215 ; Ciobanu, Dosoftei, p. 114-124. Il semble que le dernier ait été réalisé à partir de l'édition publiée à Kiev par Moghila, en 1629, Ibidem, p. 124 ; Запаско, Ісаєвич, Пам'ятки, p. 48 (nº 186).

51. Ciobanu, Dosoftei, p. 83-92. Dosoftei a même voulu se rendre à Moscou, mais il a été obligé de s'arrêter à Kiev où il a visité le monastère des Grottes (1684), Ibidem, p. 87-89; Ursu, Dascălu, Mărturii, p. 57-62, 86-92.

52. Il est fort probable que Mitrofan a appris l'art de la typographie dans les terres ruthènes et/ ou en Russie, Bădără, Tiparul, p. 126-130.

53. Comme ceux reçus par le moine Paisie de Cozia, pèlerin à Moscou en 1692-1693, I. Iancovescu, «Les sources russes et ukrainiennes de la peinture murale sous Constantin Brancovan », Revue Roumaine d'Histoire de l'Art. Série Beaux-Arts, 45, 2008, p. 101-116, ici p. 113. Certains livres imprimés en terres ruthènes ont été apportés en Valachie par les maîtres typographes venus de ces contrées, Z. Mihail, « La diffusion en Valachie du livre de culte slave imprimé à l'étranger au XVII ${ }^{\mathrm{e}}$ siècle », Revue des Études Sud-Est Européennes, 48 (1-4), 2010, p. 179-193, ici p. 183-184. D'autres y sont arrivés grâce aux prélats voyageurs. Ainsi, entre 1665 et 1668, Varlaam, futur métropolite de Valachie (1672-1679), se rendit dans les terres ruthènes et russes et apporta dans son pays des livres issus des presses de Kiev et L'viv, N. Şerbănescu, «Varlaam, mitropolitul Țării Româneşti, părintele tipografiei bucureștene [Varlaam, métropolite de Valachie, père de la typographie bucarestoise] », Biserica Ortodoxă Română, 76 (12), 1958, p. 1120-1158, ici p. 1125.

54. Bezviconi, Contribuții, p. 89-92 ; Mihail, « La diffusion », p. 183-184.

55. P.P. Panaitescu, « Petru Movilă și românii » [Pierre Moghila et les Roumains], Biserica Ortodoxă Română, 40 (9-10), 1942, p. 403-420 [= Petru Movilă. Studii, p. 76-97]; D.P. Bogdan, «Les Enseignements de Pierre Movilă adressés à son frère Moise Movilă », Cyrillomethodianum 1 (1971), p. 1-25 ; Gh. Mihăilă, « Două scrieri literare ale lui Petru Movilă adresate compatrioților săi [Deux écrits littéraires de Pierre Moghila adressés à ses compatriotes] », in Idem, Contribuții la istoria culturii, p. 183-228.

56. P.P. Panaitescu, «O carte necunoscută a lui Petru Movilă dedicată lui Matei Basarab [Un livre inconnu de Pierre Moghila dédicacé à Matei Basarab] ", in Omagiu lui Petre Constantinescu-Iași cu prilejul împlinirii a 70 de ani [Hommage à Petre Constantinescu-Iași 
nous intéresse ici, Mihail Cantacuzino, le neveu du prince Brâncoveanu, a fait don d'un Triôdion pour le Carême (L'viv, 1664) au monastère de Sinaia, sa fondation ${ }^{57}$.

Si la question de la langue source de la traduction du Synodikon semble résolue, sans toutefois pouvoir préciser quelle édition du Triôdion slave a été employée ${ }^{58}$, il n'en est pas de même quant à l'auteur de la version roumaine du texte. Notre hypothèse, qui exige cependant des arguments supplémentaires, est qu'elle a été réalisée par Mitrofan lui-même, dont la connaissance du slavon et du grec est attestée ${ }^{59}$. Son expérience comme typographe et éditeur nous incite à le recommander comme traducteur putatif du Synodikon.

\section{Le Synodikon en roumain : le spectre de la damnation éternelle}

Nous avons vu que la publication du Triôdion en Valachie était aussi opportune que nécessaire. Mais qu'en était-il du Synodikon ? Pourquoi publier le Synodikon de l'Orthodoxie en roumain et pourquoi précisément en 1700 ?

L'explication tient au statut que ce texte détenait dans la pensée et la pratique liturgique de l'Église d'Orient. Lu le premier dimanche du Grand Carême, aussi appelé « dimanche de l'Orthodoxie » ou « dimanche du Triomphe de l'Orthodoxie ", pour célébrer la victoire sur l'iconoclasme, le Synodikon était devenu un pilier de la lutte contre tout égarement dogmatique. Il s'agit tout autant d'un texte qui proclame de manière synodale l'unité de et dans la juste foi que d'une arme vouée à détruire les hérésies qui divisent la communauté des fidèles, car il remémore les combats victorieux contre les hétérodoxes. Cette fonction de lieu de mémoire concerne aussi l'institution monarchique, puisque ce texte fait valoir la mission du souverain de protecteur, institué par Dieu, de la juste foi et de l'Église. Le Triomphe de l'Orthodoxie, dont le Synodikon est le témoin le plus éloquent, est donc également un triomphe du pouvoir monarchique ${ }^{60}$, une manière de célébrer le roi juste et bien aimant du Christ qui met de l'ordre dans son troupeau, à l'image

pour son $70^{\mathrm{e}}$ anniversaire], Bucarest : Academia RPR, 1965, p. 295-301 [= Petru Movilă. Studii, p. 102-110; voir les précisions des éditeurs, p. 142, avec bibliographie].

57. Comme l'atteste la notice manuscrite (datée du 5 novembre 1694) sur la page de titre de l'exemplaire conservé à la BAR, Bucarest (cote CR III 85835).

58. Certaines particularités du texte indiquent qu'il s'agit d'une édition produite dans les terres ruthènes. Nous aborderons ce sujet dans une étude distincte.

59. Bădără, Tiparul,p. 127. Mitrofan est aussi le commanditaire d'un dictionnaire latin-roumain, réalisé par Teodor Corbea, lettré et diplomate à la cour de Brâncoveanu ; voir A.-M. Gherman, éd., Dictiones latinae cum valachica interpretatione [Mots latins avec traduction roumaine], Cluj-Napoca : Clusium, 2001.

60. À Constantinople, le Synodikon était déclamé depuis l'ambon «comme l'Évangile et l'homélie et avec les mêmes formules d'introduction », lors d'une cérémonie liturgique spéciale à laquelle participait l'empereur, Gouillard, « Le Synodikon », p. 13. Il en était de même à Moscou, comme l'atteste Paul d'Alep, V. Shevzov, « Resistance and Accommodation : The Rite of Orthodoxy in Modern Russia ", in N. Chrissidis, C. Potter, et al., éds., Religion and Identity in Russia and the Soviet Union, Bloomington, IN : Slavica Publishers, 2011, p. 165-189. Nous remercions Nikolaos Chrissidis de nous avoir communiqué cet article. 
du Grand Pasteur lui-même. Dans le contexte de la disparition de l'Empire chrétien d'Orient, la proclamation annuelle des dogmes de la religion et l'anathème lancé sur les hérésiarques revêtent une importance accrue. Ainsi, la publication du Synodikon en roumain peut être considérée comme un appel adressé aux orthodoxes de langue roumaine à faire face ensemble au danger de l'hérésie et du schisme. Plus concrètement, la référence à la victoire des images émet un clair message antiprotestant, alors que la partie la plus récente du texte, sur la controverse palamite et l'uniatisme, est dirigée contre les Latins et les uniates.

Ce message était-il nécessaire ? La réponse est positive, car l'Église orthodoxe se sentait menacée par deux grands dangers : l'offensive protestante, surtout calviniste ${ }^{61}$, d'un côté, et l'activité missionnaire du Saint-Siège, notamment dans les terres ruthènes ${ }^{62}$ et en Transylvanie ${ }^{63}$, de l'autre. Dans les deux cas, la question n'était pas seulement religieuse, elle était aussi politique : soumis à la Porte ottomane, les orthodoxes rêvaient d'une libération prochaine du pouvoir des « infi-

61. Le problème calviniste devait beaucoup à l'héritage et à la mémoire du patriarche

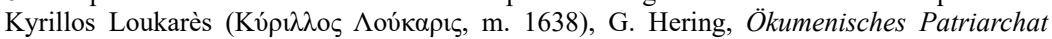
und europäische Politik 1620-1638, Wiesbaden : Franz Steiner, 1968 (version grecque revue

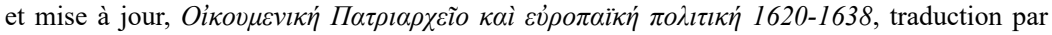
D. Kourtovik, Athènes : MIET, 1992). Ces aspects sont brillament analysés par O.-V. Olar, La boutique de Théophile. Les relations du patriarche de Constantinople Kyrillos Loukaris (1570-1638) avec la Réforme, thèse de doctorat, École des hautes études en sciences sociales, Paris, 2015. Voir aussi Idem, « Paroles de pierre. Kyrillos Loukaris et les débats religieux du XVII $^{\mathrm{e}}$ siècle ", Archaevs, 14 (1-4), 2010, p. 165-196. Sur la question calviniste dans l'espace roumain, notamment en Transylvanie, voir A. Dumitran, Religie ortodoxă - religie reformată. Ipostaze ale identității confesionale a românilor din Transilvania în secolele XVI-XVII [Religion orthodoxe - religion réformée. Hypostases de l'identité confessionnelle des Roumains de Transylvanie, $\mathrm{XVI}^{\mathrm{e}}-\mathrm{XVII}^{\mathrm{e}} \mathrm{s}$.], Cluj-Napoca : Neramia Napoca, 2004, et la récente synthèse, écrite pourtant dans une perspective confessionnelle, d'I.I. Croitoru, Ortodoxia şi Apusul în tradiţia spirituală a românilor. Unitatea Ortodoxiei şi apărarea credinţei ortodoxe în faţa propagandei protestante din secolul al XVII-lea [L'orthodoxie et l'Occident dans la tradition spirituelle des Roumains. L'unité de l'orthodoxie et la défense de la foi orthodoxe face à la propagande protestante au XVII ${ }^{\mathrm{e}}$ s.], 2, Târgovişte : Cetatea de Scaun, 2012.

62. Voir J. Macha SJ, Ecclesiastical Unification : A Theoretical Framework together with Case Studies from the History of Latin Byzantine Relations, Rome : Pontificium Institutum Orientalium Studiorum, 1974, p. 284-300.

63. Il s'agit de l'union d'une partie des orthodoxes de Transylvanie avec Rome (1697-1701) ; voir M. Bernath, Habsburg und die Anfänge der rümanischen Nationsbildung, Leyde : Brill, 1972 et, plus récemment, R. Nedici, Formarea identității confesionale greco-catolice în Transilvania veacului al XVIII-lea : Biserică şi comunitate [La formation de l'identité confessionnelle gréco-catholique en Transylvanie au XVIII ${ }^{\mathrm{e}} \mathrm{s}$. : Église et communauté], Bucarest : Universitatea București, 2013. Le principal artisan de l'union a été le cardinal Léopold Kollonitch, cf. J. Maurer, Cardinal Leopold Graf Kollonitsch, Primas von Ungarn : Sein Leben und sein Wirken, Innsbruck : F. Rauch, 1887 ; B.A. Hodson, « The Development of Habsburg Policy in Hungary and the 'Einrichtungswerk' of Cardinal Kollonich, 1683-1690 », Austrian History Yearbook, 38, 2007, p. 92-107. Pour les missions catholiques, voir L. Periș, Le missioni gesuite in Transilvania e Moldavia nel Seicento, Cluj-Napoca : Fundația pentru Studii Europene, 1998 ; V. Barbu, Purgatoriul misionarilor : Contrareforma în Țările Române $\hat{\imath}$ secolul al XVII-lea [Le Purgatoire des missionnaires : la Contre-Réforme dans les pays roumains au $\mathrm{XVII}^{\mathrm{e}}$ s.], Bucarest : Academiei, 2008. Pour les missions catholiques en terres grecques, voir

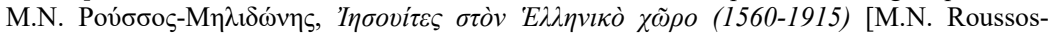
Mèlidonès, Les jésuites dans l'espace grec, 1560-1915], Athènes : KEO, 1991. Pour le contexte général, voir D. Tollet, «La reconquête catholique en Europe Centrale », Mélanges de l'École française de Rome. Italie et Méditerrannée, 109 (2), 1997, p. 825-852. 
dèles », certes, mais craignaient en même temps le danger d'une conversion par la force à la foi romaine. Autrement dit, ils se retrouvaient, une fois de plus, entre le turban ottoman et la tiare pontificale ${ }^{64}$.

Le prince valaque, protecteur attitré de l'orthodoxie, notamment des orthodoxes de langue roumaine ${ }^{65}$, ne pouvait pas voir l'offensive catholique en Transylvanie et ailleurs d'un bon œil. Du point de vue religieux, le prosélytisme catholique menaçait l'identité spirituelle de ses sujets et protégés ; du point de vue politique, il constituait un obstacle sérieux face à toute tentative d'alliance antiottomane avec les puissances catholiques et notamment avec le Saint-Empire, objectif que Brâncoveanu poursuivit tout au long de son règne ${ }^{66}$.

Pourtant, à la différence de nombre d'autres livres religieux imprimés en Valachie, la préface-dédicace du Triôdion de Buzău manque de toute nuance polémique.

Cela correspond à l'attitude générale de Constantin Brâncoveanu envers l'Union, faite de flexibilité et de prudence plutôt que d'agressivité qui, au demeurant, n'aurait pu mener nulle part dans le contexte de l'époque ${ }^{67}$. En effet, après la victoire chrétienne aux portes de Vienne (1683) et le basculement de la Transylvanie dans le camp des Habsbourg (1699), toute action directe du prince valaque

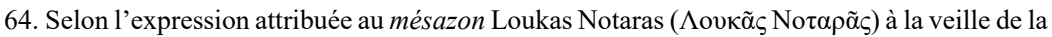
conquête ottomane de Constantinople, H. Evert-Kappesowa, « La tiare ou le turban », Byzan-

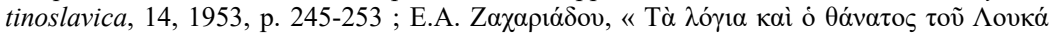

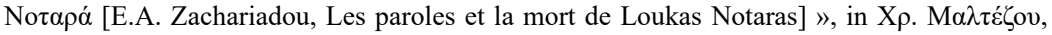

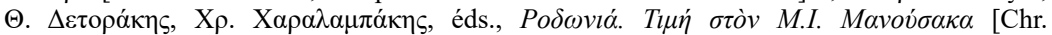
Maltezou, Th. Detorakès, Chr. Charalampakès, éds, Rodonia. Hommage à M.I.Manousakas], Rhetymnon, Panepistèmiou Krètès, 1994, 1, p. 135-146 ; D.R. Reinsch, « Lieber der Turban als was ? Bemerkungen zum Dictum des Lukas Notaras ", in C.N. Constantinides et al., éds., $\Phi I \Lambda E \Lambda \Lambda H N$. Studies in Honour of Robert Browning, Venise : Istituto Ellenico di Studi Bizantini e Postbizantini, 1996, p. 377-389.

65. Ainsi, par exemple, le Candiote catholique Nikolaos Papadopoulos Komnènos, professeur de droit canon à l'université de Padoue, le considérait comme l'homme clef en vue d'une éventuelle conversion des orthodoxes au catholicisme, « per l'autorità, per le richezze, per l'amor che tutti gli portano, per l'intelligenza con la Moldavia », V. Vasiliu, « Constantin Brâncoveanu e il Cattolicesimo. Alcune notizie nuove intorno alla sua politica religiosa », Ephemeris Dacoromana, 3, 1925, p. 110-128, ici p. 115 (lettre à Nikolaos Boubouli, le 27 octobre 1702).

66. Pour la diplomatie de Brâncoveanu, voir les titres cités en note 8 et A. Pippidi, « Constantin Brâncoveanu ca diplomat [Le diplomate Constantin Brâncoveanu] ", Academia Română. Memoriile Secției de Științe Istorice, 4e série, 4, 1988, p. 87-94 ; P. Cernovodeanu, In vâltoarea primejdiilor : Politica externă şi diplomaţia promovate de Constantin Brâncoveanu (1688-1714) [Dans la tourmente des périls : la politique extérieure et la diplomatie de Constantin Brâncoveanu, 1688-1714], Bucarest : Silex, 1997.

67. R. Nedici, « Dezacordul religios în context urban: mobilizarea elitelor laice ortodoxe din Transilvania în confruntarea cu Biserica Unită la începutul secolului al XVIII-lea [Le désaccord religieux en contexte urbain : la mobilisation des élites laïques de Transylvanie dans la confrontation avec l'Église uniate au début du XVIII ${ }^{\mathrm{e}}$ s.] », in S. Câlția, éd., Lumea orașului : cercetări de istorie urbană [Le monde de la ville : recherches d'histoire urbaine], Bucarest : Universitatea București, 2013, p. 103-142 ; Idem, « Coordonatele unei atitudini : Constantin Brâncoveanu şi Biserica românilor din Transilvania [Les coordonnées d'une attitude : Constantin Brâncoveanu et l'Église des Roumains de Transylvanie] », https://www.academia. edu/12957822/Coordonatele_unei_atitudini_Constantin_Br\%C3\%A2ncoveanu_\%C8\%99i_ Biserica_rom\%C3\%A2nilor_din_Transilvania (consulté le 20 septembre 2015). 
pour ou contre les Latins risquait d'envoyer un message politique immédiat ${ }^{68}$. Le secrétaire florentin de Brâncoveanu, Anton Maria del Chiaro, l'a très bien vu : la Valachie se situait entre deux empires qui se disputaient le contrôle de la region, ce qui obligeait le prince à jouer le jeu de la prudence et de l'équilibre. Un jeu terriblement dangereux par ailleurs ${ }^{69}$, comme en témoigne le conflit qui a opposé Brâncoveanu aux Autrichiens en 1689-169070. Fort de cette expérience, le prince valaque a choisi de poursuivre une politique souple, préférant souvent des manœuvres indirectes à une action frontale, stratégie qui s'est avérée gagnante, au moins sur la courte et la moyenne durée ${ }^{71}$.

Une seule lettre de Brâncoveanu est connue, qui incite les Roumains orthodoxes de Transylvanie à résister à l'Union (datée du 5 juillet 1701) ${ }^{72}$. Elle tentait

68. Kollonitch avertissait d'ailleurs le métropolite Teodosie que Brâncoveanu n'avait aucun droit de juridiction en Transylvanie et le métropolite, son sujet, n'en possédait pas plus en matière religieuse. En reprochant à Teodosie son attitude à l'égard du métropolite uniate Athanasie Anghel, Kollonitch attirait également son attention sur le fait que ces gestes constituaient « materiam gravissimarum dissensonum et perturbationum inter augustissimum et invictissimum Romanorum imperatorem et principem vestrul Valachiae », N. Nilles, Symbolae ad illustrandam historiam Ecclesiae orientalis in terris coronae S. Stephani, Oeniponte: F. Rauch, 1885, 1, p. 352-354.

69. « La Valachia è situata nel mezzo de' due Imperi. Questi formano una bilancia : chi n'è principe deve inpigare sua politica nel mantenerla in un perfetto equilibrio. Se la bilancia trabocca oltre il dovere dalla parte de Turchi, corre pericolo di perder il principato e la libertà nelle mani de Tedeschi [...] Se, vice versa, dalla parte de Tedeschi o di altre potenze christiane, ciò basta a Turchi, anco di falso pretesto per privarlo del principato, delle facoltà e finalmente della vita », Anton Maria Del Chiaro, Istoria delle moderne rivoluzioni della Valachia. Con la descrizione del paese, natura, costumi, riti e religione degli abitanti, éd. par N. Iorga, Bucarest : s.n., 1914, p. 149. Selon Carlo Ruzzini, le délégué de Venise au Congrès de Karlowitz, Brâncoveanu maîtrisait parfaitement l'art du compromis et de la duplicité : « Il principe [...] presente di Valacchia passa con fama di saggio, et attento à bilanciarsi con desterità frà i riguardi di Cesare e della Porta, usando anco l'arte di portar avvisi, che possan esser utili, ò grati, hor all'uno, hor all'altro Partito ; indagando con osservatione i succesi della Christianità, e raccoglendo con la stessa della Turchia ", Fontes Rerum Austriacarum. Zweite Abteilung. Diplomata et Acta, 27, Die Relationen der Botschafter Venedigs über Deutschland und Österreich in Siebzehnten Jahrhundert, Vienne : K.K. Hof- und Staatsdruckerei, 1867, p. 406 (19 décembre 1699).

70. Le conflit s'acheva par la bataille de Zărnești, dans laquelle les troupes turco-tatares et valaques infligèrent une cuisante défaite aux Autrichiens, P. Binder, « Cronologia campaniei din 1690 [La chronologie de la campagne de 1690] », in P. Cernovodeanu, Fl. Constantiniu, éds., Constantin Brâncoveanu, Bucarest : Academiei RSR, 1989, p. 113-123 ; C. Rezachevici, Constantin Brâncoveanu. Zărnești 1690, Bucarest : Militară, 1989.

71. Preuve en est qu'il a obtenu le titre de prince de l'Empire, en 1695, N. Iorga, « Les diplômes impériaux de Constantin Brâncoveanu, prince de Valachie ", Revue Historique du Sud-Est Européen, 14 (7-9), 1937, p. 177-186.

72. Cette lettre n'est pas adressée à tous les orthodoxes de langue roumaine de Transylvanie, mais seulement à ceux de la région de Braşov, où le prince lui-même avait fondé un monastère (Sâmbăta de Sus). Brâncoveanu les assurait qu'Athanasie ne pouvait pas aller trop loin dans son apostasie, car il n'en avait pas la permission de Vienne, ce qui d'ailleurs n'était pas conforme à la réalité. Il promettait aussi d'intervenir auprès de l'empereur Léopold afin que la foi orthodoxe soit respectée, St. Stinghe, Documente privitoare la trecutul Romînilor din Şchei [Documents concernant le passé des Roumains de Şchei], 1, Braşov : Ciurcu \& Comp., 1901, p. 15-16. Voir aussi D. Dumitran, « Rezistenţa ortodoxă împotriva unirii religioase în Braşov şi Țara Bârsei » [La résistance contre l'Union religieuse à Braşov et dans Țara Bârsei], Annales Universitatis Apulensis. Series Historica 9 (2), 2005, p. 53-61 ; Nedici, « Dezacordul religios » ; Idem, " Coordonatele ». 
de réparer l'inévitable, car le métropolite orthodoxe transylvain Athanasie Anghel avait déjà reçu la consécration en rite uniate à Vienne (le 25 mars 1701) ${ }^{73}$. Le prince a cherché à intervenir dans l'affaire par d'autres voies et a œuvré même pour une alliance avec des notabilités hongroises de Transylvanie, de confession protestante, contre les catholiques, et surtout contre les jésuites, les principaux promoteurs de $1^{\prime}$ Union $^{74}$. Il a également essayé d'exercer des pressions diplomatiques sur la cour de Vienne. Il l'a fait d'abord par l'intermédiaire de Lord William Paget, ancien médiateur lors des négociations de Karlowitz, qui, sur son chemin de retour de Constantinople, s'est présenté à l'empereur Léopold $(1702)^{75}$. La mission de Paget a échoué, peut-être à cause de l'implication du diplomate anglais dans l'action revendicative de la noblesse transylvaine, majoritairement protestante, mécontente du prosélytisme catholique soutenu par Vienne ${ }^{76}$. Enfin, toujours en 1702, Brâncoveanu a demandé à Pierre le Grand d'intervenir auprès de Léopold, pour que celui-ci garantisse la liberté religieuse des orthodoxes de la région de Braşov, étroitement liés à la Valachie ${ }^{77}$.

Par ailleurs, et toujours dans une logique d'action discrète, le prince a fourni des moyens matériels à l'Église orthodoxe transylvaine, il a entretenu tout un réseau d'agents d'influence censés agir dans la principauté intracarpatique ${ }^{78}$ et a contribué directement à la production de livres de culte destinés aux orthodoxes de langue roumaine. Ainsi, en 1699, alors que l'offensive unioniste batttait son plein, il a envoyé en Transylvanie un des meilleurs typographes valaques, Mihail Ștefanovici (ou Iștvanovici), avec la mission d'y faire imprimer des livres de culte en roumain, dont le premier fut le Chiriacodromion (anthologie de sermons et lectures des Évangiles à lire le dimanche), publié à Alba Iulia, le siège métropolitain. Bien qu'imprimé sur un territoire appartenant aux Habsbourg et patronné par le métropolite (encore) orthodoxe local Athanasie Anghel, le livre contient des louanges à l'adresse du prince valaque. En effet, Ștefanovici se réfère à Brâncoveanu comme à l'« illuminateur de la foi orthodoxe », qu'il ne cesse de renforcer par l'entremise

73. À cette occasion, Athanasie s'engageait à rompre toute relation avec les instances politiques et ecclésiastiques valaques.

74. Nedici, « Dezacordul religios »; Idem, « Coordonatele ».

75. Le message de Brâncoveanu était appuyé par celui du patriarche œcuménique adressé à l'empereur, Nilles, Symbolae, 1, p. 354-355.

76. Nedici, « Coordonatele ».

77. Şt. Meteş, « Din relaţiile noastre cu Rusia : fraţii David şi Teodor Corbea din Braşov în slujba poporului român ca luptători contra unirii cu Roma, ca diplomaţi şi scriitori [De nos relations avec la Russie : les frères David et Teodor Corbea de Braşov au service du peuple roumain comme combattants contre l'Union avec Rome, diplomates et écrivains] », Mitropolia Ardealului, 5 (11-12), 1960, p. 847-848.

78. I.A. Pop, « Domnia lui Constantin Brâncoveanu și românii din Transilvania - realitate istorică și reflectare în istoriografia românească transilvăneană din secolul XVIII [Le règne de Constantin Brâncoveanu et les Roumains de Transylvanie - la réalité historique et sa réflexion dans l'historiographie roumaine de Transylvanie au XVIII ${ }^{\mathrm{e}} \mathrm{s}$.] », in Cernovodeanu, Constantiniu, éds., Constantin Brâncoveanu, p. 59-73 ; Nedici, « Dezacordul religios »; Idem, « Coordonatele ». 
des livres qu'il fait imprimer pour les Roumains, et comme au vrai patron du siège métropolitain orthodoxe de Transylvanie ${ }^{79}$.

Ces actions sont étayées par un vaste programme de consolidation de l'orthodoxie en Valachie et dans l'Empire ottoman, à travers nombre de donations matérielles ${ }^{80}$ et une intense activité typographique censée produire des livres de culte destinés à tous les peuples orthodoxes, condition essentielle pour améliorer la qualité de l'enseignement et de la pratique liturgiques ${ }^{81}$. De même, les presses valaques publient un nombre important d'ouvrages en roumain voués à diffuser les principes de la morale chrétienne : les Perles de saint Jean Chrysostome, par les frères Greceanu (Mărgăritare, Bucarest, 1691), Invățătura creștinească ([Enseignements chrétiens], Snagov, 1700), Floarea darurilor (version roumaine de Fiore di virtù, Snagov, 1700), Invățătura de șeapte taini ([Enseignements sur les sept

79. Dans la préface-dédicace, le typographe souligne l'importance de l'ouvrage, qui manquait cruellement aux églises et aux fidèles orthodoxes de Transylvanie, $B R V, 1$, p. 375.

80. Sur les donations de Brâncoveanu aux lieux de culte des terres bulgares, voir P. Bojčeva, " Sur un acte de donation de Constantin Brâncoveanu à l'église orthodoxe de Tărnovo ", Études Balkaniques, 37 (1), 2001, p. 71-79 ; Eadem, « Un document de Constantin Brâncoveanu relatif au monastère de Kapinovo (Saint-Nicolas) près de Tărnovo », in P.-H. Stahl, éd., Omagiu Virgil Cândea la 75 de ani [Hommage à Virgil Cândea pour ses 75 ans], Bucarest : Roza Vânturilor, 2002, 1, p. 97-107 ; P. Zahariuc, « În mijlocul străinătății. Două hrisoave de danie pentru mănăstirea Lipnic din Bulgaria [À l'étranger. Deux actes de donation pour le monastère de Lipnic, en Bulgarie] », in Idem, De la Iași la Muntele Athos : Studii și documente de istoria Bisericii [De Iași au Mont Athos : études et documents sur l'histoire de l'Église], Iași : Universitatea «Al.I. Cuza », 2008, p. 209-221 ; I. Gergova, " Das älteste Gedenkbuch des Rila-Klosters », Bulgarian Historical Review, 36 (1-2), 2009, p. 164-179. Sur les donations pour les lieux de culte serbes, voir E. Turdeanu, « Din vechile schimburi culturale dintre români şi iugoslavi [Des échanges culturels d'autrefois entre Roumains et Yougoslaves] », Cercetări Literare, 3, 1939, p. 141-258, ici p. 180. Sur les donations au Mont Athos, voir P. Cernovodeanu, « Constantin Brâncoveanu şi Muntele Athos [Constantin Brâncoveanu et le Mont Athos] », Revista Istorică 9 (3-4), 1998, p. 115-122 ; I. Moldoveanu, Contribuţii la istoria relaţiilor Țărilor române cu Muntele Athos (1650-1863) [Contributions à l'histoire des relations des Pays roumains avec le Mont Athos, 1650-1863], Bucarest : Institutul Biblic și de Misiune Ortodoxă al Bisericii Ortodoxe Române, 2002, surtout p. 292 (liste des donations). Voir aussi T.Gh. Bulat, « Daniile lui Constantin Brâncoveanu pentru Orientul orthodox [Les donations de Constantin Brâncoveanu pour l'Orient orthodoxe] », Biserica Ortodoxă Română, 82 (9-10), 1964, p. 931-944.

81. Sur les livres grecs publiés en Valachie, voir E. Turdeanu, « Le livre grec en Russie : l'apport des presses de Moldavie et de Valachie », Revue des Études Slaves, 26 (1-4), 1950, p. 69-87 [= Études de littérature roumaine et d'écrits slaves et grecs des Principautés Roumaines, Leyde :

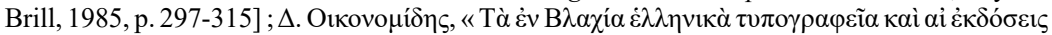
$\alpha$ $\tau \tilde{\omega} v, 1642-1821$ [D. Oikonomidès, La typographie grecque de Valachie et ses productions,

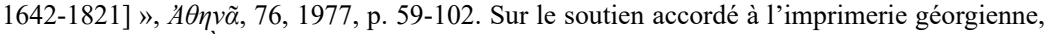
voir A. Pippidi, « À propos des débuts de l'imprimerie en Géorgie », in E. Siupiur, Z. Mihail et al., éds., Impact de l'imprimerie et rayonnement intellectuel des Pays Roumains, Bucarest : Biblioteca Bucureștilor, 2009, p. 25-40. Sur l'aide accordée aux orthodoxes de langue arabe, voir I. Feodorov, "The Romanian Contribution to Arabic Printing », dans le même volume, p. 41-62 ; V.G. Tchentsova, « La correspondance du patriarche d'Antioche Athanase IV Dabbâs avec la cour russe : à propos de l'imprimerie arabe d'Alep », in Travaux du Symposium international «Le livre. La Roumanie. L'Europe ». Troisième édition. 20-24 septembre 2010, Bucarest : Biblioteca Bucureștilor, 2011, 1, p. 46-58 ; I. Feodorov, Tipar pentru creștinii arabi. Antim Ivireanul, Atanasie Dabbās și Silvestru al Antiohiei [Typographie pour les chrétiens arabes. Antim Ivireanul, Athanase Dabbās et Silvestre d'Antioche], Brăila : Istros, 2016. 
mystères], Buzău, 1702) ou Învățătură bisericească [Enseignements ecclésiastiques], par le métropolite Antim Ivireanul (Târgoviște, 1710) (22. $^{82}$.

Si ces faits semblent illustrer une stratégie plutôt défensive, il faut aussi prendre en compte le fait que la typographie valaque produit des livres polémiques en $\operatorname{grec}^{83}$, mais aussi certaines versions roumaines, dont Carte sau lumină ([Livre ou lumière], Snagov, 1699), la traduction du traité antilatin de Maximos le Pélopon-

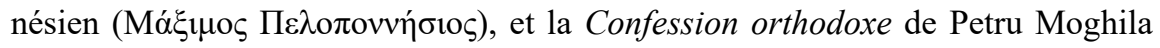
(Pravoslavnica mărturisire, Buzău, 1691), qui précède une version grecque publiée en 1699 , à Snagov ${ }^{84}$. Les deux derniers livres sont imprimés sur l'ordre et sous le patronage du prince, le but étant, comme le souligne Radu Greceanu, un des traducteurs du premier ouvrage (avec son frère Șerban), de porter à la connaissance du peuple roumain les vérités de la juste foi ${ }^{85}$. De même, la polémique anticatholique et anticalviniste est bien présente dans la peinture murale des lieux de culte que Brâncoveanu fait ériger ou rénover en Valachie ${ }^{86}$.

S'il ne pouvait - ou ne voulait - agir personnellement ou de manière directe contre le catholicisme romain, le prince valaque a offert toutefois des moyens et

82. Pour tous ces livres, voir BRV, 1, p. 315-321, 390-392, 393-394, 433-435 et 539, 481 et 548.

83. Le sentiment antilatin était partagé par nombre de personnages de l'entourage princier. Par une lettre envoyée de Valachie, l'oncle et principal conseiller de Brâncoveanu, le stolnic [écuyer tranchant] Constantin Cantacuzino, faisait savoir à l'agent du prince à Moscou, David

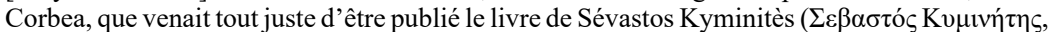

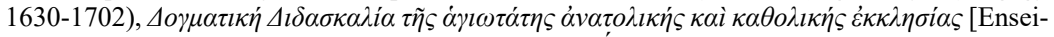
gnement dogmatique de la très sainte et catholique Église d'Orient], Bucarest, 1703. Selon lui, le livre était dirigé « contre ceux qui se prétendent orthodoxes, mais sont nourris par le papisme », à savoir les uniates. Une traduction en slavon était en préparation, D.P. Bogdan, «Cărți rusești în Țara Românească sub Constantin Brâncoveanu [Livres russes dans la Valachie de Constantin Brâncoveanu] », Biserica Ortodoxă Română, 74 (6-7), 1956, p. 543-557, ici

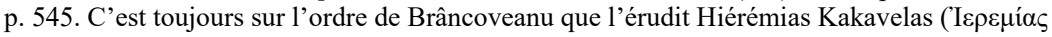
K $\alpha \kappa \alpha \beta \varepsilon \dot{\lambda} \alpha \varsigma$ ) traduit en grec vernaculaire le livre de Bartolomeo Platina de Sacchi, De vitis ac gestis summorum pontificum (Venise, 1479) l'accompagnant de commentaires fort critiques, surtout au sujet du Filioque (1687), A. Camariano-Cioran, « Jérémie Cacavela et ses relations avec les principautés roumaines ", Revue des Études Sud-Est Européennes, 3 (1-2), 1965, p. 165-190, ici p. 418-420.

84. $B R V, 1$, p. 321 et p. 378 , respectivemment.

85. Ibidem, p. 323. Des doutes ont été émis concernant la circulation de ces livres en Transylvanie, Nedici, « Dezacordul religios »; Idem, « Coordonatele ». Ces doutes ne peuvent pas concerner les deux ouvrages mentionnés ci-dessus, cf. I. Cristache-Panait, Circulația cărții vechi bucureștene în Transilvania [La circulation du vieux livre bucarestois en Transylvanie], Bucarest : Biblioteca Bucureștilor, 1998, p. 11-12 et 22. Certains autres livres de ce genre étaient en préparation. Ainsi, dans la préface aux Mărgăritare (Bucarest, 1691), les éditeurs annonçaient la parution prochaine d'une traduction roumaine de l'ouvrage antilatin de Nekta-

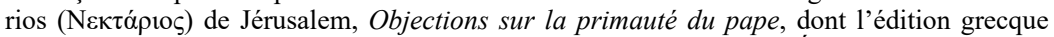

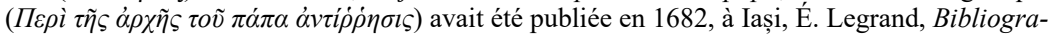
phie hellénique ou description raisonnée des ouvrages publiés par des Grecs au dix-septième siècle, 2, P. : Alphonse Picard et Fils, 1894, p. 401-408 (n ${ }^{\circ}$ 568) ; BRV, 1, p. 251-257. Ce livre n'est jamais paru.

86. C'est le cas du monastère de Hurezi, sa fondation éminente, I. Iancovescu, « Mânăstirea Hurezi [Le monastère de Hurezi] », in Repertoriul picturilor murale brâncoveneşti [Le répertoire des peintures murales de l'époque de Brâncoveanu], 1, Judeţul Vâlcea [Le département de Vâlcea], Bucarest : UNARTE, 2008, p. 47. 
un large champ d'action au plus résolu des polémistes orthodoxes du temps, le patriarche de Jérusalem, Dosithéos II ( $\Delta$ oбí $\operatorname{co\varsigma }$ B $\left.^{\prime}, 1669-1707\right)^{87}$. Hormis sa vaste politique éditoriale anticatholique et antiprotestante ${ }^{88}$, le patriarche a entretenu des relations avec la compagnie marchande hellénophone de Sibiu, une sorte de « cinquième colonne » dans le combat contre l'uniatisme ${ }^{89}$, et a pris des positions tranchantes contre les uniates. En janvier 1698, il a donné au métropolite orthodoxe transylvain, Athanasie Anghel, des instructions strictes concernant la manière d'officier dans les églises se trouvant sous sa juridiction ${ }^{90}$. Le but est très clairement exprimé : il fallait observer sans faille « les Dogmes, les Mystères et les coutumes de l'Église d'Orient », tels qu'ils étaient formulés dans la Confession orthodoxe, récemment traduite en roumain et publiée à Bucarest en $1691^{91}$. Pour tout problème,

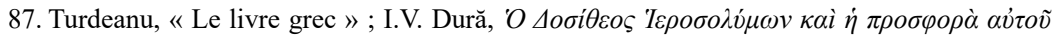

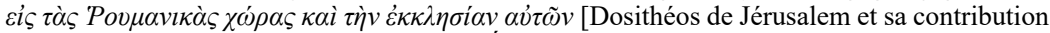
[à l'histoire] des Pays roumains et de leurs Églises], Athènes : s.n., 1977, p. 56-62 et 237-257. Sur l'activité typographique de Dosithéos, voir A. Palmieri, Dositeo patriarca greco di Gerusalemme (1641-1707). Contributo alla storia della teologia greco-ortodossa nel secolo XVII, Florence : Libreria editrice fiorentina, 1909 ; Turdeanu, «Le livre grec »; Idem, " Les controverses des Jansénistes et la création de l'imprimerie grecque en Moldavie », in Mélanges de linguistique et de littérature romanes offerts à Mario Roques, P. : Marcel Didier, 1952, 3, p. 281-302 [= Études de littérature roumaine, p. 275-296] ; K1.-P. Todt, « Dositheos II. von Jerusalem », in C.G. Conticello, V. Conticello, éds., La théologie byzantine et sa tradition, 2, (XIII ${ }^{e}-X I X^{e}$ s.), Turnhout : Brepols, 2002, p. 659-720 ; O. Olar, " A time to speak. The printing activity of Dositheos Notaras, patriarch of Jerusalem († 1707) », Annales Universitatis Apulensis. Series Historica, 15 (2), 2011, p. 35-45 ; Idem, «Point indignes d'occuper une place dans la Bibliothèque du Roi. La diffusion et l'écho des livres grecs publiés dans les Pays Roumains aux soins de Dosithée de Jérusalem († 1707) », Transylvanian Review, 21, 2012 (Supliment 1), p. 169-182.

88. Dans une lettre adressée à Kollonitch, le jésuite Jacob Caschodus attire l'attention sur l'activité typographique de Dosithéos, qui nuisait considérablement aux intérêts de Rome dans la région : "Patriarcha Hierosolymitanus græcus, pessimus Schismaticus, fere singulis annis editis libris calumniis mendaciis plenis, fidem Romanam traducit, eosque libros per Moldaviam, Valachiam et forte etiam per Hungariam distribuit, qui libri sunt perniciosissimi », Nilles, Symbolce, 1, p. 105 (Constantinople, 25 juillet 1701). Le Saint-Siège avait bien compris le rôle joué par Brâncoveanu dans ces actions et admettait qu'il était impossible de le faire changer d'attitude par la force ; mieux valait le traiter avec « bonnes manières » et déférence : « Questi libri si stampano nello stato del Principe di Valacchia con la sua autorità e Protettione e, essendo Principe Assoluto e scismatico, nulla si potrebbe rimediar col cattivo, ma solamente con le buone manière e con ingegnosa Politica », Vasiliu, « Constantin Brâncoveanu », p. 118.

89. Sur le rôle culturel des compagnies marchandes de Transylvanie, voir surtout Ath.E. Karathanassis, L'hellénisme en Transylvanie : l'activité culturelle, nationale et religieuse des compagnies commerciales helléniques de Sibiu et de Braşov aux XVIII-XIX ${ }^{e}$ siècles, Thessalonique : Institute for Balkan Studies, 1989.

90. M. Săsăujan, « Die Instruktion des Patriarchen Dositheos für Athanasie »/« Instrucţiunea patriarhului Dositei pentru Atanasie », in Die Union der Rumänen Siebenbürgens mit der Kirche von Rom/Unirea românilor transilvăneni cu Biserica Romei, Bucarest : Enciclopedică, 2010, p. 196-214. Athanasie avait passé des mois à Bucarest, précisément pour être bien instruit selon les enseignements de l'Église d'Orient. Lors de son ordination par le métropolite Teodosie, en présence de Dosithéos lui-même, il a prononcé et signé une profession de foi.

91. Il s'agit de la traduction roumaine de la Confession attribuée au métropolite de Kiev, Pierre Moghila, BRV, 1, p. 321-324. Pour le texte grec, voir La Confession orthodoxe de Pierre Moghila, Métropolite de Kiev (1633-1646), approuvée par les Patriarches grecs du $X V I I^{e}$ siècle, éd. par A. Malvy SJ et M. Viller SJ, Rome - P. : Pontificium Institutum Orientalium

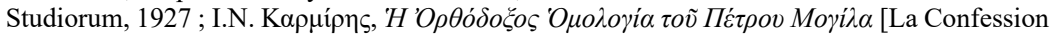


Athanasie était censé se rapporter à l'original grec de l'ouvrage, faire appel au métropolite valaque, son supérieur hiérarchique, ou bien s'adresser directement au Patriarcat œcuménique.

La fidélité d'Athanasie n'as pas duré longtemps, ce qui a provoqué une réaction particulièrement dure de Dosithéos. En novembre 1701, il a écrit au métropolite transylvain devenu uniate, afin de le convaincre de revenir à la juste foi, sous peine d'anathématisation. Le ton est tranchant : comment est-il possible de quitter

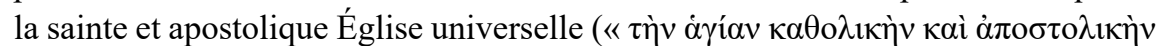

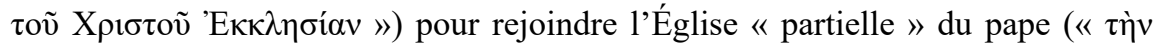

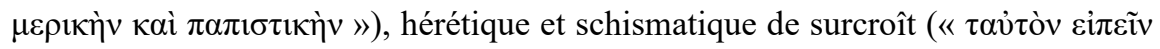

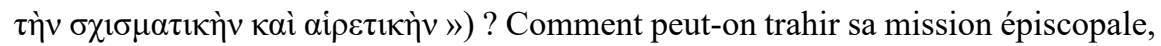
devenir modèle et initiateur du mal (« $\check{\xi} \xi \rho \chi 0 \varsigma \tau \tilde{\eta} \varsigma \kappa \alpha \kappa i ́ \alpha \varsigma$ ») et se transformer de

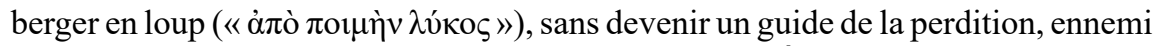

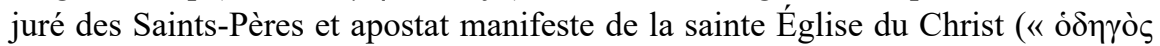

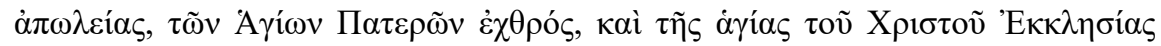

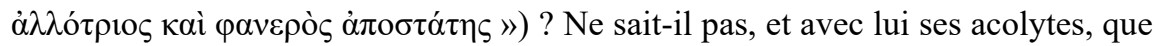
l'Église romaine n'est, en fait, que la monarchie pervertie du pape et que cette monarchie, chose inacceptable pour les Pères et pour la vraie Église, l'orthodoxe,

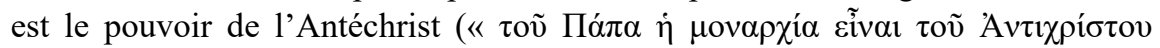
$\dot{\eta} \dot{\varepsilon} \xi o v \sigma i ́ \alpha »)^{92}$ ?

Dosithéos a agit souvent de concert avec le métropolite valaque Teodosie, qui était aussi le chef spirituel de l'Église orthodoxe de Transylvanie, et il est certain que leurs actions ont joui de l'accord et du support de Brâncoveanu ${ }^{93}$. Il faut

orthodoxe de Pierre Moghila], Athènes : s.n., 1953. Voir aussi D. Mârşanu, « Old News Concerning Peter Mogila's Orthodox Confession: The First Edition Revisited », Archoevs 10 (1-2), 2006, p. 273-286 ; O. Olar, «Un temps pour parler. Dosithée de Jérusalem et le synode de Jassy (1642)», Analele Putnei, 10 (1), 2014, p. 215-250. Pour le texte roumain, voir 'O $\rho \theta \delta ́ \delta o \xi o \varsigma$

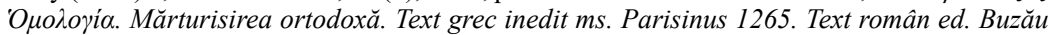
1691 [La Confession orthodoxe. Texte grec inédit, ms. Parisinus 1265. Texte roumain, éd. Buzău 1691], éd. par N.M. Popescu et Gh.I. Moisescu, Bucarest : Mitropolia Bucovinei, 1942 ; Mărturisirea de credinţă a Bisericii Ortodoxe 1642 [La confession de foi de 1'Église orthodoxe, 1642], éd. par Al. Elian, Bucarest : Institutul Biblic și de Misiune Ortodoxă al Bisericii Ortodoxe Române, 1981. Voir aussi S. Paschalides, « Concilium Constantinopolitanum - $1642 »$, in Melloni, éd., The Great Councils, p. 253-264.

92. É. Legrand, Recueil de documents grecs concernant les relations du Patriarcat de Jérusalem avec la Roumanie (1569-1728), P. : Maisonneuve, 1903², p. 38-40 ; E. de Hurmuzaki, Documente privitoare la istoria Românilor [Documents concernant l'histoire des Roumains], XIV/1, éd. par N. Iorga, Bucarest : Socec \& Co., 1915, p. 342-344 (n 398, novembre 1701). Ce dernier syntagme est extrait de la lettre envoyée par Dosithéos au notable transylvain Stefan Rácz (novembre 1701), Ibidem, p. 340-341 (n 397). L'expression apparaît plus d'une fois dans les écrits du patriarche. Notons qu'elle a fait histoire dans la culture russe, C.G. De Michelis, I nomi dell'avversario. Il «papa-anticristo » nella cultura russa, Turin : Albert Meynier, 1989.

93. Le 6 décembre 1702, l'agent de Brâncoveanu à Moscou, David Corbea, déclara aux autorités locales que le prince, ses parents et proches conseillers, Constantin et Mihail Cantacuzino, et le patriarche Dosithéos avaient décidé ensemble de solliciter l'aide du tsar afin de libérer les orthodoxes du joug des Turcs infidèles et d'agir contre les « hérétiques » ennemis de l'Église d'Orient, Исторические связи народов СССР и Румынии в XV- начале ХVIII в [Les relations historiques entre les peuples de l'URSS et la Roumanie, $\mathrm{XV}^{\mathrm{e}}$-début du $\mathrm{XVIII}{ }^{\mathrm{e}} \mathrm{s}$.], 3 , 1673-1711, M. : Nauka 1970, p. 176 ( $\mathrm{n}^{\circ}$ 51). Cette attitude était aussi partagée par le métropolite 
remarquer, à ce point, l'attitude du prince et du métropolite valaques, vraisemblablement concertée avec Dosithéos, qui se trouvait alors en Valachie, quant à la diffusion du Triôdion de 1700. Sur les dix exemplaires du livre découverts en Transylvanie ${ }^{94}$, au moins deux ont été donnés par le prince aux églises et monastères de la région de Braşov, centre de résistance contre l'uniatisme se trouvant sous sa protection $^{95}$. En même temps, lorsqu'Athanasie Anghel, tout juste converti à l'uniatisme, a demandé au métropolite valaque des livres de culte récemment publiés (l'Oktoéchos, le Triôdion et le Pentèkostarion), il a eu droit à une sévère remontrance. Par une lettre du 2 mai 1702, Teodosie lui a fait savoir que ni le prince ni lui-même ne voulaient fournir aux «papistes » des saints livres de l'Église d'Orient, car ils ne souhaitent pas que leur contenu soit perverti dans le sens des conceptions hérétiques ${ }^{96}$. Questions de foi, et pour cette raison traitées par le chef de l'Église, l'uniatisme et les livres de culte n'en sont pas moins des sujets politiques, que le prince valaque n'entend pas laisser au gré du hasard.

Du reste, les deux prélats ne pouvaient pas se dispenser du support fourni par Brâncoveanu ou agir sans son accord. Ainsi, la lettre (8 novembre 1700) que Teodosie adressait au patriarche moscovite Adrian (Адриан) a été portée à desti-

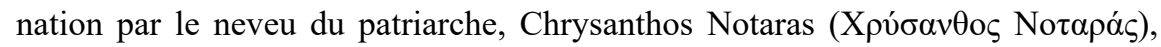
en voyage à Moscou ${ }^{97}$. Mais ce n'est pas la seule mission que Chrysanthos devait

moldave Dosoftei, qui entretenait des relations assez étroites avec le patriarche de Jérusalem, P.P. Panaitescu, « Patriarhul Dositei al Ierusalimului şi Mitropolitul Dosoftei al Moldovei. Cu prilejul unei scrisori inedite [Le patriarche Dosithéos de Jérusalem et le métropolite Dosoftei de Moldavie. À l'occasion d'une lettre inédite] », Biserica Ortodoxă Română, 64 (1-3), 1946,

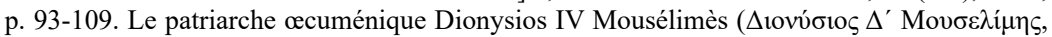
1671-1694, avec interruptions), avait le même point de vue, V.G. Tchentsova, « Le clergé grec, la Russie et la Valachie à l'époque de Constantin Brâncoveanu : le témoignage des archives russes », in P. Guran, éd., Constantin Brâncoveanu et le monde orthodoxe, Bucarest : Academiei Române, 2015, p. 96-104.

94. D. Ciubotea, A. Florescu, « Răspândirea tipăriturilor brâncovenești [La diffusion des livres imprimés pendant le règne de Brâncoveanu] », in I. Pătroi, coord., Constantin Basarab Brâncoveanu, Craiova : Universitaria, 2004, p. 380-400, ici p. 387.

95. V. Oltean, Acte, documente și scrisori din Şcheii Brașovului [Actes, documents et lettres de Șcheii Brașovului], Bucarest : Minerva, 1980, p. 4-5; Tipărituri românești (1539-1750) existente la Braşov. Catalog [Livres roumains anciens se trouvant à Brașov (1539-1750). Catalogue], Brașov : Biblioteca Județeană, 1980, p. 102-109.

96. Teodosie s'arrête longuement sur l'Oktoéchos et souligne le point de controverse qui sépare la foi orthodoxe du credo romain, à savoir la question du Filioque : « in octoico sancta ecclesia nostra cantat laudes Sanctissimae Trinitati et non addit, quod Spiritus Sanctus procedat a patre et filio tanquam ab uno principio commiscente personas et superaddente principio », Nilles, Symbolae, 1, p. 345-347. Voir aussi Nedici, « Coordonatele».

97. Chrysanthos comptait sur le réseau d'influence qu'il avait tissé lors de son premier séjour dans la capitale russe (novembre 1692-février 1694), Н.Ф. Каптерев, Сношения иерусалимского патриарха Досифея с русским правительством (1669-1707 г2.) [N.F. Kapterev, Les relations du patriarche Dosithéos de Jérusalem avec le gouvernement russe, 1669-1707], M. : A.I. Snegirevoj, 1891. Voir aussi Б.Л. Фонкич, « Иерусалимский патриарх Досифей и его рукописи в Москве [B.L. Fonkič, Le patriarche Dosithéos de Jérusalem et ses manuscrits à Moscou] », Византийский Временник, 29, 1968, p. 278-279 [= Греческие рукопису и документы в России в XIV-начале XVIII в., М. : Indrik, 2003, p. 244-245]. Sur

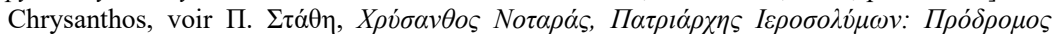

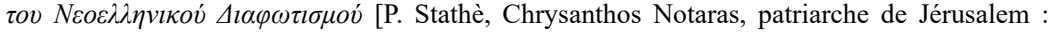


accomplir en Russie : une lettre de Brâncoveanu adressée à Pierre le Grand partait avec le même émissaire, attendu dans la capitale russe par l'agent diplomatique du prince, Panaiot $\operatorname{Radu}^{98}$. Les canaux de communication ecclésiastiques servaient donc pour la transmission des informations politiques et vice-versa.

La lettre de Teodosie est un rapport sur la situation des orthodoxes vivant « sous le joug des païens et des tyrans », de l'Orient et jusqu'aux contrées roumaines, et un appel à l'aide pathétique adressé à l'Église et au pouvoir monarchique moscovites contre les ennemis de la juste foi. Parmi ces ennemis, les Turcs ne sont nullement les pires, les Latins se révèlent beaucoup plus féroces, notamment les jésuites, qui ont trompé les orthodoxes de Transylvanie et de la Hongrie supérieure, afin de les placer sous la juridiction du pape. Le parallèle que Teodosie dresse avec les événements survenus dans le «pays polonais », où les églises russes (à savoir orthodoxes) étaient agressées par les catholiques, montre qu'il connaissait fort bien la situation, mais aussi qu'il tentait de sensibiliser le patriarche moscovite en vue d'une action commune $^{99}$. Il est vraisemblable que la lettre a été rédigée avec l'aide et sous la surveillance de Dosithéos, car l'un des épisodes relatés, et qui n'est guère nouveau, concerne l'affaire du Saint-Sépulcre, moment qui a marqué la rupture du patriarche avec la France ${ }^{100}$.

précurseur de l'Illuminisme néo-hellénique], Athènes : Kath'ēmas Anatolēs Syndesmos tōn en Athēnais Megaloscholistōn, 1999.

98. Bezviconi, Contribuții, p. 136-137. À la suite des demandes de Brâncoveanu, Pierre lui accorda le droit d'asile en cas de destitution par la Porte (19 janvier 1701).

99. S. Dragomir, « Contribuții privitoare la relațiile Bisericii românești cu Rusia în veacul XVII [Contributions concernant les relations de l'Église roumaine avec la Russie au XVII ${ }^{\mathrm{e}} \mathrm{s}$.] ", Analele Academiei Române. Memoriile Secțiunii Istorice, $2^{\mathrm{e}}$ série, 34, 1912, p. 1066-1247, ici p. 1222-1229 (original slavo-russe et traduction roumaine).

100. Sur cet épisode, voir Turdeanu, « Les controverses ». Teodosie avait constamment agi auprès du clergé de Brașov, afin de s'assurer qu'il restât ferme dans sa foi orthodoxe, C. Mușlea, Biserica Sfântul Nicolae din Șcheii Brașovului [L'église Saint-Nicolas de Șcheii Brașovului], 1, (1292-1752), Sibiu : Astra, 1943, p. 127-128 (lettre de 1701). Pour sa part, Dosithéos avait maintes fois averti le tsar du danger de l'union, Каптерев, Сношения, p. 13 (lettre du 20 juin 1698, envoyée de Valachie). Dans une des nombreuses lettres qu'il a envoyées à la cour russe (le 2 juin 1702), il affirme que Léopold I était un persécuteur des orthodoxes pire que Dioclétien, N. Russell, «From the Shield of Orthodoxy to the Tome of Joy: The Anti-Western Stance of Dositheos II of Jerusalem (1641-1707) », in G. Demacopoulos, A. Papanikolaou, éds., Orthodox Constructions of the West, Fordham : Fordham University Press, 2013, p. 71-82, ici p. 77. Une partie de cette correspondance est publiée (en traduction russe) par Н.Ф. Каптерев, Характер отношений России к православному Востоку в XVI и XVII столетияx [N.F. Kapterev, Le caractère des relations entre la Russie et l'Orient orthodoxe aux XVI ${ }^{\mathrm{e}}-\mathrm{XVII}^{\mathrm{e}} \mathrm{s}$.], M. : A.I. Snegirevoj, 1885 (surtout l'Annexe n 10) ; Idem, Сношения ; Д.А. Яламас, « Иерусалимский Патриарх Досифей и Россия. 1700-1706 гг. По материалам Российского государственного архива древних актов. Часть 2 (1701 г.) [D.A. Yalamas, Le patriarche Dosithéos de Jérusalem et la Russie. Années 1700-1706. D'après les documents du RGADA (Archives Nationales des actes anciens de la Russie), II ${ }^{\mathrm{e}}$ partie, 1701] », in Россия и Христианский Восток [La Russie et l'Orient chrétien], 2-3, M. : Indrik, 2004, p. $472-492$ (textes originaux et traduction russe) ; Idem, « Иерусалимский Патриарх Досифей и Россия. 1700-1706 гг. По материалам Российского государственного архива древних актов, Часть 1 (1700 г.) [Le patriarche Dosithéos de Jérusalem et la Russie. Années 1700-1706. D'après les doucments du RGADA. $\mathrm{I}^{\mathrm{re}}$ partie, 1700] », in Россия и Христианский Восток [La Russie et l'Orient chrétien], 4-5, M. : JaSK, 2015, p. 593-647. 
Le point fort de cette action commune est la lettre envoyée par Teodosie et Dosithéos aux orthodoxes de Transylvanie (3 juillet 1702), pour leur faire savoir que le patriarche œcuménique a anathématisé Athanasie Anghel, en tant que traître de la foi et nouveau Judas, ainsi que tous ceux qui ont trahi la foi orthodoxe en choisissant l'union avec Rome. À ce titre, il ne fallait plus désormais s'adresser à Athanasie comme à un détenteur du don de la prêtrise et possesseur de la grâce divine. S'il n'était pas souhaitable d'insulter les simples fidèles trompés par les uniates ou de les tenir pour ennemis - cela allait à l'encontre de la bonne morale orthodoxe -, il fallait en revanche se rapporter à Athanasie et aux prêtres uniates comme à des non-chrétiens, car ils étaient désormais exclus de la sainte Église du Christ ${ }^{101}$.

Tout en modulant le ton par endroits, cette lettre suit la ligne de conduite insufflée par le Patriarcat œcuménique à l'égard des «traîtres de la foi ». En effet, l'acte

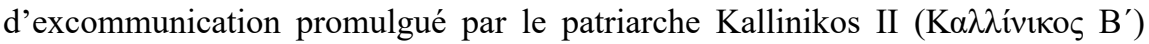
contre le « malitiosus hypocrita Athanasius vel potius Satanasius » [le malicieux hypocrite Athanasie ou [pour] mieux [dire] Satanasie] (août 1701) est tranchant. Le métropolite transylvain est excommunié de manière formelle et son nom voué à la damnation éternelle, peine spirituelle qu'il doit partager avec tous ceux qui le suivraient dans l'hérésie ${ }^{102}$. On retrouve là l'esprit du Synodikon de l'Orthodoxie, dont la lecture lors du premier dimanche du Grand Carême ne sera pas désormais sans rapport avec les événements vécus.

C'était précisément cet esprit que le texte publié à Buzău devait communiquer aux fidèles, et ceci non pas en slavon ou en grec, mais bien dans la langue parlée par le peuple. Cependant, le texte roumain du Synodikon suit la tradition du Synodikon imprimé grec et slave et ne présente aucune particularité locale, ni au niveau des anathèmes ni en ce qui concerne les laudes; le souci majeur de ses éditeurs semble donc d'avoir voulu donner une version roumaine de ce texte classique de l'orthodoxie et non pas de l'adapter aux réalités locales, comme ce fut le cas en Russie, par exemple.

\section{Le Synodikon en roumain : la promesse du paradis}

Hormis ces éléments, il se peut que d'autres facteurs aient également joué un rôle dans la publication du Synodikon de l'Orthodoxie en roumain sous le patronage de

101. La lettre est adressée par Dosithéos, mais signée par les deux prélats, Stinghe, Documente, 1, p. 34-37.

102. «Quod si quipiam ausi fuerint se cum illo induere et simul celebrare vel illi honorem dare archiepiscopalem vel manum osculari, vel benedictionem et sanctificationem ejus acceptare, vel eleemosynam ecclesiae illius dare, si sacerdotes fuerint, a sacerdotali dignitate sint exclusi, et qui exclusionem nil curant, ab ipso summo Deo sint excommunicati, ut rei aeternae damnationis. Si laici fuerint, sive senes sive juvenes, sint condamnati et post mortem etiam ligati suamque mercedem cum Juda habeant, nunquam ex ecclesia profectum capiant, a grege Christi exclusi sint et in ecclesia non acceptentur, non sanctificentur, sed excommunicati sint, donec Athanasium dereliquerint », Nilles, Symbolae, 1, p. 344-350. 
Constantin Brâncoveanu. Ces facteurs tiennent d'après nous aux rapports entre le prince valaque et le patriarche Dosithéos de Jérusalem.

En septembre 1690, paraissait à Bucarest un livre polémique contenant les deux écrits suivants : Manuel pour réfuter la folie des Calvinistes, rédigé par Dosithéos lui-même ${ }^{103}$ et Réfutation des chapitres calvinistes et des questions de Loukarès,

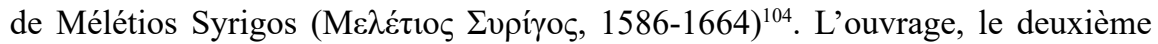
sorti des presses de la typographie du Saint-Sépulcre en Valachie, est financé par Brâncoveanu (dont les armoiries figurent au verso de la page de titre), et est le fruit du travail d'une équipe qui compte Mitrofan, ex-évêque de Huşi, Michaèl Makrès

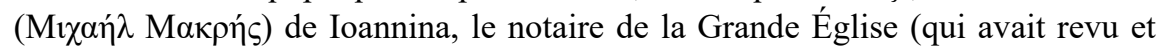
corrigé le texte), Spandonès ( $\Sigma \pi \alpha v \delta \omega v \eta ́ s)$, le grand dikaiophylax du Patriarcat œcuménique, et le neveu et futur successeur de Dosithéos, Chrysanthos.

Dans la préface-dédicace du livre adressée au prince valaque, Dosithéos esquisse un vrai programme théologico-politique. Le mal, identifié ici par l'hérésie, existe depuis toujours, écrit-il : les temps anciens ont connu de nombreux

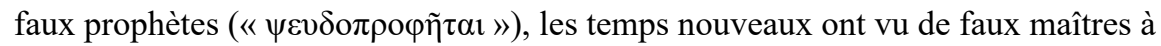
penser, qui ont introduit dans l'Église des hérésies abominables (« غ̇v $\tau \tilde{\eta} \dot{\varepsilon} \kappa \kappa \lambda \eta \sigma i ́ \alpha$

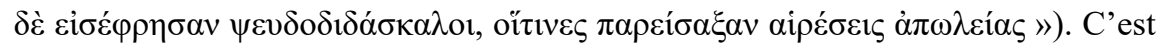
pour les combattre et les détruire que Dieu a institué dans le monde une arme double : d'une part, les docteurs de l'Église, censés dissiper le mensonge par leur parole pure et leurs écrits et, de l'autre, les monarques orthodoxes, dont la mission est de donner force de loi aux enseignements dispensés par les premiers. Ainsi, les

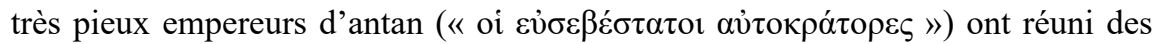
saints synodes pour mettre un terme aux malentendus en matière de foi et promulguer l'orthodoxie à travers des lois, édits, décrets et autres moyens (littéralement, " moyens de combat », « $\alpha \gamma \tilde{\omega} v \alpha \varsigma »)$. Pourtant, malgré les efforts conjoints des empereurs et des hauts prélats, le problème reste de grande actualité, car le monde chrétien, d'Occident et d'Orient, est hanté par la pire des hérésies, le calvinisme. Pour la combattre, le prince moldave Vasile Lupu, de concert avec le métropolite de Kiev, Pierre Moghila, et en sa présence, a convoqué un synode à Iași (1642), qui

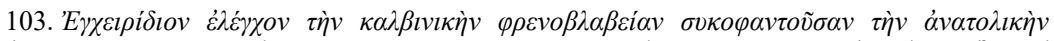

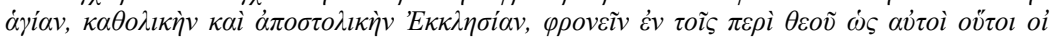

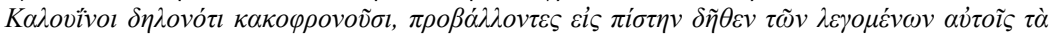

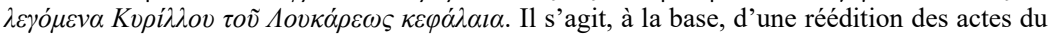
synode que Dosithéos avait réuni en 1672, mais contenant nombre d'arguments nouveaux, V. Kontouma, «La Confession de Foi de Dosithée de Jérusalem : les versions de 1672 et de 1690 », in M.-H. Blanchet, F. Gabriel, éds., L'Union à l'épreuve du formulaire. Professions de foi entre Églises d'Orient et d'Occident (XIII ${ }^{e}-X V I I I^{e}$ s.), Leuven - P. - Bristol, CT : Peeters, 2016, p. 341-372. L'édition critique des actes de ce synode est publiée par V. Kontouma et S. Garnier, "Concilium Hyerosolimitanum - 1672 », in Melloni, éd., The Great Councils, p. 265-328.

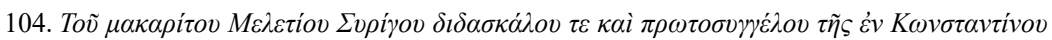

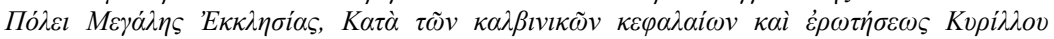

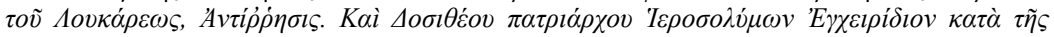
$\kappa \alpha \lambda \beta \imath v \iota \eta_{\varsigma} \varsigma \rho \varepsilon v o \beta \lambda \alpha \beta \varepsilon i \alpha \varsigma$, Legrand, Bibliographie... dix-septième siècle, 2, p. 458-473 $\left(\mathrm{n}^{\circ} 632\right) ; B R V, 1$, p. 298-315 (n $\left.{ }^{\circ} 90\right)$. La publication du traité de Syrigos était préparée depuis longtemps, Hurmuzaki, Documente, XIV/1, p. 209-210 (n 293, lettre du grand drogman de la

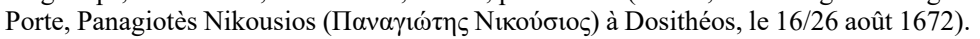


a condamné « l'impiété de Calvin $»^{105}$. C'est à cette occasion et à la demande du prince que Syrigos a rédigé le traité que la Providence divine a ensuite mis entre les mains du patriarche de Jérusalem, au moment même où le combat pour la juste foi était devenu des plus rudes. Le retrouvant, Dosithéos s'est fait un devoir de le publier, car les fidèles en avaient cruellement besoin : n'avait-il pas été sollicité, dix ans plus tôt, par les orthodoxes de Transylvanie pour les aider à combattre les calvinistes ? Que pouvait-il leur offrir de mieux que le livre de Syrigos ? Mais comment faire, cependant, sans argent pour le publier ni l'appui d'un monarque bien aimant du Christ et de Sa Vraie Parole qui soutienne l'entreprise ? En d'autres termes, Dosithéos, nouveau Moghila, avait besoin d'un nouveau Vasile Lupu ${ }^{106}$.

Le destin a œuvré pour le patriarche : le prince Șerban Cantacuzino décédé subitement (1688), le trône valaque a échu à Brâncoveanu. L'homme était à la hauteur de l'œuvre, tant par sa foi immaculée que par ses vertus et le sang noble qu'il avait hérité de ses ancêtres, sur les deux lignées, paternelle et maternelle à la fois. En effet, continue le patriarche, du côté paternel, le prince est issu des Basarab $^{107}$, des monarques qui ont accompli nombre de bonnes choses pour leur pays et pour l'Église orthodoxe de partout, notamment pour le Saint-Sépulcre ${ }^{108}$. Du côté maternel, l'ascendance du nouveau prince se révèle encore plus illustre, car il pouvait s'enorgueillir de compter pas moins de cinq empereurs chrétiens parmi ses ancêtres : Alexis ${ }^{\text {er }}$ Comnène (1081-1118), Jean II Comnène (1118-1143), Manuel I Comnène (1143-1180), Jean VI Cantacuzène (1347-1354) et Mathieu Cantacuzène (co-empereur, 1353-1357). Fait fort parlant, Dosithéos souligne que les ancêtres de Brâncoveanu ne sont pas seulement des empereurs, mais aussi des

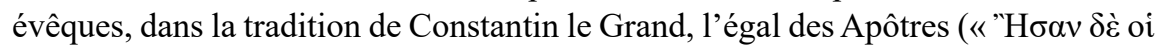

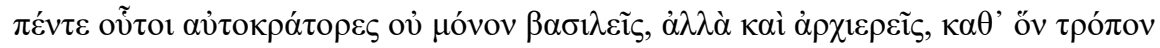

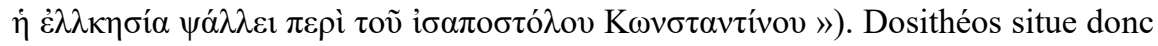
Brâncoveanu dans la droite ligne des pieux empereurs d'antan en lui assignant la mission sacrée de défendre la juste foi professée par les nouveaux docteurs de l'orthodoxie : Syrigos et lui-même, les auteurs des deux écrits qui venaient de voir le jour à Bucarest. La bonne vieille théorie byzantine de la symphonie des autorités

105. Legrand, Bibliographie... dix-septième siècle, 2, p. 463-466 ; BRV, 1, p. 303-308. Sur ce synode et sa posterité, voir Olar, «Un temps pour parler », p. 246-248.

106. Dosithéos propose que les deux ouvrages imprimés en grec soient traduits en arabe, en roumain et en slavon. La traduction en slavon fut réalisée à Moscou, le 25 août 1691, et celle en arabe en 1690, Turdeanu, "Le livre grec »; O.B. Strakhov, The Byzantine Culture in Muscovite Rus'. The Case of Evfimii Chudovskii (1620-1705), Cologne - Weimar - Vienne : Böhlau, 1998, p. 150, 166-167.

107. Pour la généalogie de Brâncoveanu, voir Şt.S. Gorovei, M.S. Rădulescu, « Constantin Basarab Brâncoveanu. Strămoşii, înrudirile şi calea spre tron [Constantin Basarab Brâncoveanu : ses ancêtres, sa parenté et la voie vers le trône] ", Anuarul Institutului de Istorie și Arheologie « A.D. Xenopol », 27, 1990, p. 223-237.

108. Ce qui était vrai, et Dosithéos le savait bien, car Matei Basarab (1632-1654) avait donné 7000 grosia au patriarche Paisius ${ }^{\mathrm{er}}$ afin qu'il demarrât la réparation de l'église de Bethléem, N. Stoicescu, Matei Basarab, Bucarest : Academiei RSR, p. 102, note 68. 
est ainsi ressuscitée et transformée par le patriarche en arme de combat contre les hérésies qui troublaient le monde orthodoxe de son temps.

Connu depuis longtemps, ce texte a toujours été vu comme un exercice de captatio benevolentiae censé ouvrir au patriarche les portes de la générosité du prince valaque ${ }^{109}$. Cette interprétation est sans doute correcte, mais elle reste simpliste. En passant en revue les exploits des ancêtres (très) lointains de Brâncoveanu, Dosithéos lui donne ici également une vraie leçon d'histoire et d'histoire de la théologie et esquisse tout un programme pour l'avenir. Plus encore, chaque référence qu'il mentionne dans la dédicace renvoie, d'une part, à un paragraphe du Synodikon de l'Orthodoxie et, de l'autre, au moins à un titre d'ouvrage que Dosithéos voulait voir imprimé dans l'immédiat.

Ainsi, en passant en revue les hauts faits d'Alexis Comnène, Dosithéos souligne son ardent combat pour le bien de l'Église : il a fait anathématiser en synode le faux moine Neilos (Nعĩnos); avec l'aide de l'évêque de Philippopolis et d'Eustratios, le métropolite de Nicée, il a ramené les Pauliciens à la foi orthodoxe ; il a détruit l'hérésie des Bogomiles et fait brûler sur le bûcher leur chef Vassilios ; il

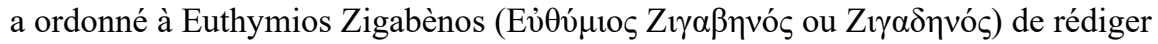

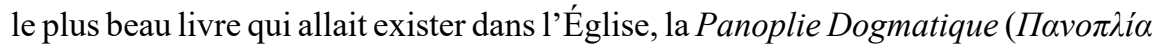
$\Delta o \gamma \mu \alpha \tau \iota \kappa \eta)$, qui combat toutes les hérésies, et il a demandé à Iôannès Phournès

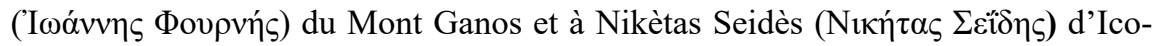
nium d'écrire contre ceux qui avaient osé se prononcer contre le Symbole de la foi. Plus encore, il s'est engagé lui-même dans une joute théologique et rhétorique concernant ces sujets avec l'évêque de Milan et l'a emporté glorieusement. Aussi, il a obtenu nombre de victoires sur les Sarrasins et libéré la sainte cité de Jérusalem ${ }^{110}$.

Quant à Jean Comnène, Dosithéos se borne à mentionner ses exploits militaires contre les Agaréens, les Perses, les Serbes et les Hongrois et sa victoire sur les « Scythes » à l'aide de l'icône de la Sainte Mère de Dieu. Sont évoquées aussi ses conquêtes en Cilicie et Syrie et la traversée de l'Euphrate ; seule la mort empêcha l'empereur d'arriver à Jérusalem pour adorer le Saint-Sépulcre du Christ.

La liste des faits illustres de Manuel Comnène est beaucoup plus longue, à commencer par le synode convoqué pour délibérer sur le syntagme « Mon Père

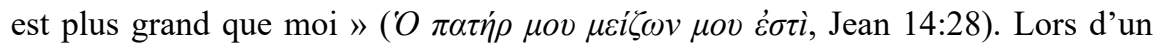
autre synode, il a fait également anathématiser ceux qui avaient blasphémé le saint mystère de l'eucharistie, en établissant de manière synodale que c'est bien le

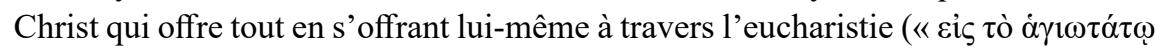

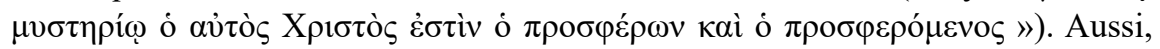
a-t-il envoyé partout dans l'empire des « éducateurs » pour répandre la parole de la vérité, tout comme l'avait jadis fait Josias en prêchant le Deutéronome. Enfin, il a

109. La seule auteure qui y voit plus est, à notre connaissance, N. Miladinova, The 'Panoplia Dogmatike' by Euthymios Zygadenos. A Study on the First Edition Published in Greek in 1710, Leyde : Brill, 2014, p. 50-56.

110. Sur la politique d'Alexis, voir É. Malamut, Alexis I Ir Comnene, P. : Ellipses, 2007. 
ordonné à Andronikos, le grand drongaire de la garde impériale, d'écrire un traité contre les ajouts apportés (par les Latins) au Symbole de foi de Nicée ${ }^{111}$.

Comme on pouvait s'y attendre, les mérites de Jean Cantacuzène ${ }^{112}$ ne sont pas moins considérables, car il a détruit en synode l'hérésie de Barlaam et Akindynos, celle de Grègoras et celle de Jean, le patriarche de Constantinople ; plus que

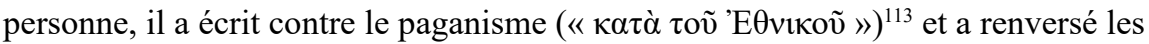
principes de l'impie Prochoros, en montrant, les Saints-Pères à l'appui, que la grâce et l'énergie divines ne sont pas créées.

Le patriarche n'oublie pas les hauts faits de Mathieu Cantacuzène, sa bravoure, surtout dans les guerres contre les Perses (Ottomans), son savoir et ses vertus. Chassé du trône par Jean Paléologue, le rejeton du grand Jean Cantacuzène suit l'exemple de son père : acceptant son sort avec stoïcisme, il choisit de méditer sur les biens éternels de l'esprit. Ainsi, il a rédigé des commentaires au Cantique des Cantiques et à la Sagesse de Salomon et plusieurs autres ouvrages, rendant de ce fait un service encore plus grand à l'humanité qu'il n'en a rendu au trône impérial.

Nul doute qu'Alexis $I^{\text {er }}$ Comnène fut un grand défenseur de l'orthodoxie, quoiqu'il le fût à son propre profit et suivant ses propres intérêts. C'est pendant son règne, et en bonne mesure grâce à ses actions, que le Synodikon de l'Orthodoxie a subi les premières modifications, de nouveaux noms y étant ajoutés à la suite d'une série de synodes. C'est toujours lui qui a transformé le Synodikon en arme théologico-politique, alors que Manuel n'a fait que marcher dans ses pas ${ }^{114}$. Ainsi, le nom du moine Neilos, condamné par un synode pendant le règne d'Alexis (entre 1084 et 1094), figure effectivement parmi ceux anathématisés dans le Synodikon ${ }^{115}$. La question paulicienne, devenue très épineuse, a exigé une large mobilisation de volonté politique de la part de l'empereur, ce dont on peut trouver la

111. Sur l'époque de Manuel, voir P. Magdalino, The Empire of Manuel I Komnenos, 1143-1180, Cambridge : Cambridge University Press, 1993.

112. Sur Jean Cantacuzène, voir surtout D.M. Nicol, The Reluctant Emperor : A Biography of John Cantacuzene, Byzantine Emperor and Monk, c. 1295-1383, Cambridge : Cambridge University Press, 1996.

113. Dosithéos fait référence à l'Apologie contre Mahomet ; voir K1.-P. Todt, Kaiser Johannes VI. Kantakuzenos und der Islam : politische Realität und theologische Polemik im palaiologenzeitlichen Byzanz, Würzburg : Echter-Oros, 1991. Cet écrit a aussi circulé dans les Pays roumains, traduit en roumain par l'érudit Nicolae le Spathaire (Milescu), V. Cândea, « Une version roumaine du XVII ${ }^{\mathrm{e}}$ siècle de l'Apologie contre Mahomet de Jean Cantacuzène », Revue des Études Sud-Est Européennes, 4 (1-2), 1966, p. 233-237 ; Ioan Cantacuzino, Patru apologii pentru religia creştină şi Patru oraţii traduse în limba română la mijlocul secolului al XVII-lea de Nicolae Spătarul (Milescu) [ «Quatre apologies pour la religion chrétienne » et «Quatre oraisons » traduites en roumain au milieu du XVII ${ }^{\text {e }}$. par Nicolae le Spathaire (Milescu)], éd. par E. Dima, Iaşi : Universitatea « Al.I. Cuza », 2011.

114. Voir M. Angold, Church and Society in Byzantium under the Comneni, 1081-1261, Cambridge : Cambridge University Press, 1995, p. 50 et suiv. ; Malamut, Alexis $I^{\text {er }}$ Comnène, p. 191-266.

115. Gouillard, « Le Synodikon », p. 202-206 ; N.G. Garsoïan, « L'abjuration du moine Nil de Calabre », Byzantinoslavica, 35 (1), 1974, p. 12-27 [= Armenia between Byzantium and the Sasanians, Londres : Variorum, 1985]. 


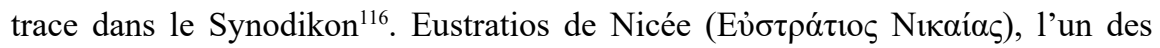
proches d'Alexis, partie prenante dans le combat contre les Pauliciens et participant aux disputes théologiques du temps ${ }^{117}$, était familier à Dosithéos, car le patriarche avait l'intention de publier certains de ses écrits ${ }^{118}$. Ici, toutefois, Dosithéos perd de vue, par erreur ou à bon escient, un élément important : Eustratios avait été lui-même condamné par un synode convoqué sous Alexis et son nom anathématisé dans le Synodikon (1117), ${ }^{119}$ ce qui était aussi le cas des bogomiles, Vassilios en tête de liste ${ }^{120}$. Quant à la Panoplie Dogmatique, traité dirigé contre les Latins, les Arméniens et les Pauliciens, elle a été imprimée en Valachie sous le patronage de Brâncoveanu lui-même (1710) ${ }^{121}$.

116. Sur cette hérésie, voir N.G. Garsoïan, The Paulician Heresy, P. - La Haye : Mouton, 1967.

117. Sur Eustratios de Nicée, voir Gouillard, « Le Synodikon », p. 206-210 ; V. Grumel, « Autour du voyage de Pierre Grossolanus, archevêque de Milan à Constantinople, en 1112. Notes d'histoire et de littérature », Échos d'Orient, 32 (169), 1933, p. 22-33, ici p. 25-27 ; H.-G. Beck, Kirche und theologische Literatur im Byzantinischen Reich, Munich : C.H. Beck, 1959, p. 618-619.

118. Lors de son premier voyage à Moscou (1692), Chrysanthos Notaras a transporté 18 manuscrits et 11 livres grecs imprimés, qui devaient constituer la base d'un vaste programme d'édition conçu par Dosithéos et dont le but est dévoilé par une lettre que celui-ci adressait au tsar (1693) : combattre les idées et la propagande des schismatiques, surtout des Latins, Д.А. Яламас, « Грамота Иерусалимского патриарха Досифея об издании греческих книг в Москве [D.A. Yalamas, Lettre du patriarche Dosithéos de Jérusalem sur la publication de livres grecs à Moscou] », in Славяне и их соседи, 6, Греческий и славянский мир в средние века и раннее новое время. Сборник статей к 70-летию академика Геннадия Григорьевича Литаврина [Les Slaves et leurs voisins, 6, Le monde grec et le monde slave au Moyen Âge et au début des Temps modernes. Recueil d'articles pour le $70^{\mathrm{e}}$ anniversaires de l'académicien Gennadij Grigorevič Litavrin], M. : Indrik, 1996, p. 216-228. Un document provenant de Posol'skij Prikaz [Le bureau des Ambassades] permet de reconstituer la liste des titres que Dosithéos voulait faire imprimer. Y sont indiqués le titre de l'ouvrage, la référence au codex qui le contenait et à la feuille où se trouvait le texte respectif ; voir Каптерев, Сношения, p. 100-104, note 14 (publication) et Фонкич, « Иерусалимский патриарх » (analyse). Nous allons faire référence aux titres qui intéressent ici en citant ce dernier article et le numéro sous lequel se trouve le titre en question : Фонкич, « Иерусалимский патриарх », 23, 24 et 25. Cеs trois textes se retrouvent dans le ms. 250 de la collection de l'ancienne Bibliothèque synodale de Moscou (Московской Синодалнои Библиотеки), actuellement au Musée historique d'État de Moscou (Государственный Исторический Музей), Арх. Владимир, Систематическое описание рукописей Московской Синодальной (Патриаршей) библиотеки. Часть I. Рукописи греческие [Arh. Vladimir, Description systématique des manuscrits de la Bibliothèque synodale de Moscou. Première partie. Manuscrits grecs], M. : s.n., 1894, p. $337\left(\mathrm{n}^{\circ} 25\right)$, $340-341\left(n^{\circ} 80\right)$ et $337\left(n^{\circ} 27\right)$. Tous les trois sont copiés d'après des textes inclus dans le ms. 239 de la même collection (XIv e siècle).

119. Gouillard, « Le Synodikon », p. 206-210 ; P. Joannou, « Eustrate de Nicée. Trois pièces inédites de son procès (1117) », Revue des Études Byzantines 10 (1), 1952, p. 35-46 ; Angold, Church and Society, p. 73-75.

120. Gouillard, « Le Synodikon », p. 233, notes 426 et 427 . Voir aussi D. Gress-Wright, «Bogomilism in Constantinople», Byzantion, 47, 1977, p. 163-185 ; A. Rigo, « Il processo del bogomilo Basilio (1099 ca.) : una riconsiderazione », Orientalia Christiana Periodica, 58 (1), 1992, p. 185-211 ; G. Vespignani, «"Basilio, el monje bogomilo”, condena de un heterodoxo en Bizancio », in M. del Mar Marcos Sánchez, éd., Herejes en la historia, Madrid : Trotta, 2009, p. 101-120.

121. $B R V, 1$, p. 482-483. Selon N. Miladinova, l'auteure de l'édition critique du texte, la publication de cet ouvrage est due à Dosithéos, The 'Panoplia Dogmatike', p. 37 et suiv. Voir aussi A. Rigo, « La Panoplie dogmatique d'Euthyme Zigabène : les Pères de l'Église, l'empereur et 
Les projets de Dosithéos comprenaient également la publication de certains écrits d'Iôannès Phournès, l'hégoumène du Mont Ganos ${ }^{122}$ et de Nikètas Seidès ${ }^{123}$, deux des polémistes du côté grec lors des disputationes avec Pietro Grossolano, l'évêque de Milan, en 1112 ${ }^{124}$. D'ailleurs, les disputes théologiques de cette époque-là sont investies d'une grande importance par le patriarche, si l'on en juge d'après les textes s'y rapportant qu'il voulait faire imprimer. Ainsi, en plus des écrits d'Eustratios de Nicée, Dosithéos a édité trois discours attribués

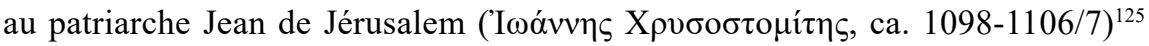
et voulait publier le traité sur les azymes de Théodoros Smyrnaios ( $\Theta \varepsilon o ́ \delta \omega \rho o \varsigma$ $\Sigma \mu v \rho v \alpha i ̃ o \varsigma){ }^{126}$, accompagné d'un écrit du patriarche Jean V d'Antioche ('I $\omega \alpha \dot{v v \eta \varsigma}$

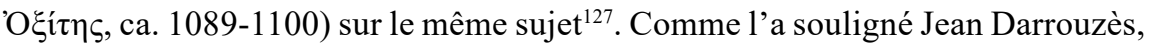
le texte de Smyrnaios « offre une parenté remarquable, dans ses lignes générales, avec l'opuscule de Théophylacte sur les erreurs des Latins $»^{128}$. Or, nous savons que Dosithéos voulait faire imprimer cet ouvrage aussi ${ }^{129}$, ainsi que d'autres

les hérésies du présent », in Idem, P. Ermilov, éds., Byzantine Theologians. The Systematization of their Own Doctrine and their Perception of Foreign Doctrines, Rome : Università degli

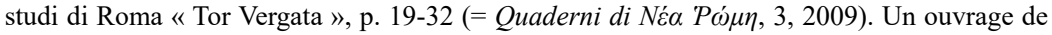
Zigabènos, portant sur la procession du Saint-Esprit, figure dans la liste des livres que Dosithéos voulait imprimer à Moscou, Фонкич, « Иерусалимский патриарх », 27 ; Владимир, Систематическое описание, ms. 239, p. 313 (n 27).

122. Фонкич, « Иерусалимский патриарх », 26 ; Владимир, Систематическое описание, ms. 250, p. 338 ( $\left.\mathrm{n}^{\circ} 32\right)$. Voir aussi Grumel, « Autour du voyage », p. 27-28.

123. Фонкич, « Иерусалимский патриарх », 28 ; Владимир, Систематическое описание, ms. 250, p. $338\left(\mathrm{n}^{\circ} 32\right), 341$ ( $\left.\mathrm{n}^{\circ} 87\right)$. Voir Grumel, «Autour du voyage », p. 28-30 ; J. Darrouzès, "Les documents byzantins du XII ${ }^{\mathrm{e}}$ siècle sur la primauté romaine », Revue des Études Byzantines, 23 (1), 1965, p. 42-88, ici p. 51-59. Les textes sont publiés par R. Gahbauer, Gegen den Primat des Papstes : Studien zu Niketas Seides. Edition, Einführung, Kommentar, Munich : Uni-Druck, 1975. Voir aussi J. Spiteris, La Critica bizantina del Primato Romano nel secolo XII, Rome : Pontificium Institutum Orientalium Studiorum, 1979, p. 44-54, 56-84.

124. Grumel, « Autour du voyage »; Darrouzès, « Les documents », p. 51-59. L'ouvrage de base pour la littérature religieuse byzantine reste Beck, Kirche und theologische Literatur. Pour un très utile répertoire des éditions d'ouvrages antilatins, voir A. Bucossi, Contra Latinos IX-XII s (https://www.academia.edu/16322597/Contra_Latinos_IX-XII_s.).

125. Tó $\dot{\alpha} \zeta \tilde{v} \mu \omega v)$; cf. P. Gautier, «Le synode des Blachernes (fin 1094). Étude prosopographique », Revue des Études Byzantines, 29 (1), 1971, p. 213-284, ici p. 230-231.

126. Фонкич, « Иерусалимский патриарх », 32 ; Владимир, Систематическое описание, ms. 250, p. $341\left(\mathrm{n}^{\circ} 94\right)$. Voir aussi Grumel, «Autour du voyage », p. 31 ; Gautier, « Le synode », p. $255-256$.

127. Ce traité apparaît deux fois dans la liste de Posol'skij Prikaz: Фонкич, « Иерусалимский патриарх », 22 et 32 (sous le même numéro que l'ouvrage de Smyrnaios, cité ci-dessus) ; Владимир, Систематическое описание, ms. 250, p. 340 ( $\left.\mathrm{n}^{\circ} 77\right)$. Voir aussi P. Gautier, «Jean V l'Oxite, patriarche d'Antioche. Notice biographique », Revue des Études Byzantines, 22 (1), 1964, p. 128-157.

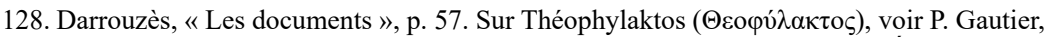
"L'épiscopat de Théophylacte Héphaistos, archevêque de Bulgarie », Revue des Études Byzantines, 21 (1), 1963, p. 159-78.

129. Фонкич, « Иерусалимский патриарх », 18 ; Владимир, Систематическое описание, ms. 250, p. 340 (n 64). Voir Patrologia Graeca, 126, col. 221-249 ; P. Gautier, Théophylacte 


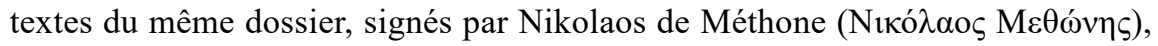
sur le Saint-Esprit, les azymes et contre les Latins ${ }^{130}$. Dans la même catégorie, il souhaitait publier un écrit adressé à l'empereur Alexis I $^{\mathrm{er}}$ Comnène, vraisemblablement en relation avec les disputationes avec Grossolano, par Nikolaos

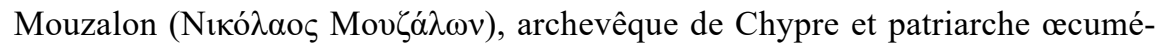
nique (1147-1151) $)^{131}$, ainsi qu'un traité sur les azymes par le métropolite Jean de Claudiopolis (fin du $\mathrm{XI}^{\mathrm{e}}$ siècle) $)^{132}$.

Dans le cas des faits pieux accomplis par Manuel Comnène, référence est faite d'abord à une des plus retentissantes controverses théologiques du $\mathrm{XII}^{\mathrm{e}}$ siècle, dans laquelle l'empereur a joué un rôle décisif. Le synode qu'il a convoqué à ce sujet en 1166 le montre bien, ainsi que le fait que les décisions prises à cette occasion-là ont été tout de suite insérées dans le Synodikon de l'Orthodoxie, dont elles constituent un chapitre bien riche ${ }^{133}$. Le deuxième point de l'exposé de Dosithéos concerne la condamnation synodale de Sotèrichos Panteugenos ( $\Sigma \omega \tau \eta \dot{p} \rho \chi \propto \varsigma$

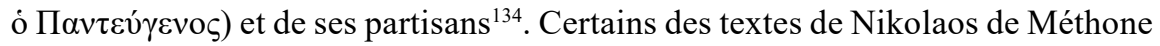
que Dosithéos voulait faire publier, et qu'il cite dans la dédicace, sont liés à cet épisode ${ }^{135}$. De même, un traité polémique, la compilation I $\varepsilon \rho \grave{\alpha} \dot{o} \pi \lambda o \theta \dot{\eta} \kappa \eta$ ([l'Arsenal sacré] autour de 1170-1175) a effectivement été écrit par Andronikos

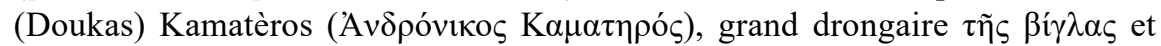
parent par alliance de l'empereur. C'est précisément lui qui, dans cet écrit, met en

d'Achrida : Discours, traités, poésies et lettres, Thessalonique : Association de recherches byzantines, 1980 , p. 247-285.

130. Фонкич, « Иерусалимский патриарх », 31 ; Владимир, Систематическое описание,

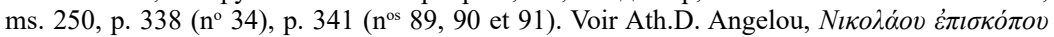

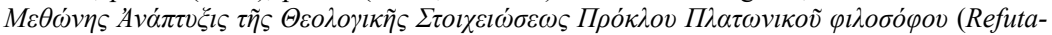
tion of Proclus' " Elements of Theology »), Athènes - Leyde : Université d'Athènes - E.J. Brill, 1984 , p. XXV (n' 1$)$ et $\mathrm{p} . \mathrm{XXVII}\left(\mathrm{n}^{\circ} 2\right)$.

131. Фонкич, « Иерусалимский патриарх », 33 ; Владимир, Систематическое описание, ms. 239, p. 313 (n 26). Voir Grumel, «Autour du voyage », p. 30-31.

132. Фонкич, « Иерусалимский патриарх », 45. Référence est faite aux mss. 239 (Владимир, Систематическое описание, p. 312, n 13), 240 (Ibidem, p. 316, $\mathrm{n}^{\circ}$ 14) et 250 (Ibidem, p. 340, $\mathrm{n}^{\circ}$ 76). Cf. Gautier, « Le synode », p. 264-265 ; A. Argyriou, « Remarques sur quelques listes grecques énumérant les hérésies latines », Byzantinische Forschungen, 4, 1972, p. 9-30 ; T.M. Kolbaba, The Byzantine Lists : Errors of the Latins, Urbana, IL : University of Illinois Press, 2000, p. 177-181.

133. Gouillard, « Le Synodikon », p. 216-226 ; G. Thetford, « The Christological Councils of 1166 and 1170 in Constantinople », St. Vladimir's Theological Quarterly, 31 (2), 1987, p. 143-169. L'édicte, gravé dans la pierre, existait encore à Constantinople, C. Mango, « The Conciliar Edict of 1166 », Dumbarton Oaks Papers, 17, 1963, p. 315-330. Dosithéos le

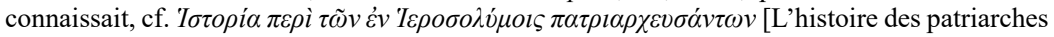
de Jérusalem], Bucarest, 1715, p. 794.

134. Gouillard, « Le Synodikon », p. 210-215 ; P. Wirth, « Zur Geschichte der Synoden wider Soterichos Panteugenos », Byzantinische Forschungen, 3, 1968, p. 260-261.

135. Ath. Angelou, « Nicholas of Methone : The Life and Works of a Twelfth-Century Bishop », in M. Mullett, R. Scott, éds., Byzantium and the Classical Tradition, Birmingham : Centre for Byzantine Studies, University of Birmingham, 1981, p. 143-148, ici p. 147. 
scène le dialogue entre l'empereur et les cardinaux ${ }^{136}$, texte que Dosithéos a tenté d'imprimer en Russie ${ }^{137}$.

Lorsqu'il passe au règne et à la personnalité de Jean Cantacuzène, le patriarche fait référence à la controverse palamite ${ }^{138}$, dans laquelle l'empereur a soutenu Grègorios Palamas et ses adeptes en écrivant contre les antipalamites ${ }^{139}$ et en présidant les synodes ayant condamné Barlaam (B $\alpha \rho \lambda \alpha \alpha ́ \mu)$, Grègorios Akindynos

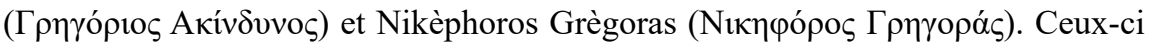
se retrouvent en tant qu'hérésiarques dans le Synodikon ${ }^{140}$. Le nom du patriarche

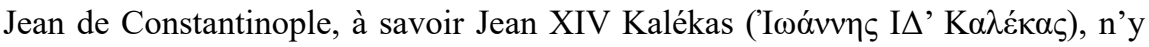
figure pas, mais son souvenir ne pouvait pas être trop cher à Dosithéos ${ }^{141}$. L' « impie

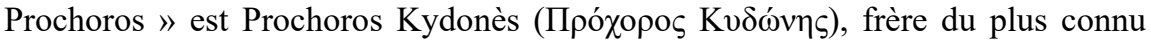
Dèmètrios $(\Delta \eta \mu \eta ́ \tau \rho ı \varsigma)$, qui ont été, tous deux, anathématisés à leur tour ${ }^{142}$.

136. A. Cataldi Palau, « L’Arsenale Sacro di Andronico Camatero. Il proemio ed il dialogo dell' imperatore con i cardinali latini : originale, imitazioni, arrangiamenti », Revue des Études Byzantines, 51 (1), 1993, p. 5-62 ; A. Bucossi, "Dialogues and Anthologies of the Sacred Arsenal by Andronikos Kamateros : Sources, Arrangements, Purposes », in C. Macé, P. Van Deun, éds., Encyclopaedic Trends in Byzantium. Proceedings of the International Conference held in Leuven, 6-8 May 2009, Leuven : Peeters, 2011, p. 269-284.

137. Фонкич, « Иерусалимский патриарх », 30. Le texte se retrouve en trois manuscrits, tous apportés par Chrysanthos en 1692 : les mss. 239, 240 et 250, Владимир, Систематическое описание, p. 314 ( $\mathrm{n}^{\text {os }} 44$ et 45$), 315\left(\mathrm{n}^{\circ} 2\right)$ et p. $342\left(\mathrm{n}^{\circ} 96\right)$; voir aussi Cataldi Palau, « L'Arsenale Sacro », p. 50, 55 ; A. Bucossi, « The Sacred Arsenal by Andronikos Kamateros, a Forgotten Treasure », in Rigo, Ermilov, éds., Byzantine Theologians, p. 33-50, ici p. 42.

138. Sur la controverse palamite, voir, entre autres, J. Meyendorff, A Study of Gregory Palamas, trad. par G. Lawrence, Londres : The Faith Press, 1964 ; Idem, Byzantine Hesychasm : Historical, Theological and Social Problems. Collected Studies, Londres : Variorum, 1974 ; A. Rigo, éd., Gregorio Palamas e oltre. Studi e documenti sulle controversie teologiche del XIV secolo bizantino, Florence : Olschki, 2004. Bibliographie très utile dans C.C. Хоружий (coord.), Исихазм: аннотированная библиография [S.S. Horužij, Hésychasme : bibliographie commentée], M. : Izdatel'skij sovet Russkoj pravoslavnoj cerkvi, 2004.

139. Voir Johannis Cantacuzeni Refutationes duae Prochorii Cydonii et Disputatione cum Paulo Patriarcha Latino Epistulis septem tradita, éd. par E. Voordeckers et Fr. Tinnefeld, Turnhout : Brepols, 1987. Dosithéos avait l'intention de publier les écrits de Cantacuzène contre Prochoros dès 1697, mais il ne put le faire, les manuscrits se trouvant à Moscou, cf. Tó $\mu o \varsigma$ $\dot{\alpha} \gamma \alpha \dot{\pi} \eta \varsigma$, p. 1.

140. Gouillard, « Le Synodikon », p. 80-85, 240-251. Sur Akindynos, voir J. Nadal Cañellas, "Gregorio Akindinos », in C.G. Conticello, V. Conticello, éds., La théologie byzantine, p. 189-256 ; Idem, La résistance d'Akindynos à Grégoire Palamas. Enquête historique, avec traduction et commentaire de quatre traités édités récemment, 2 vols., Louvain : Peeters, 2003 ; Idem, " Le rôle de Grégoire Akindynos dans la controverse hésychaste du XIV siècle à Byzance ", in J.P. Monferrer-Sala, éd., Eastern Crossroads : Essays on Medieval Christian Legacy, Piscataway, NJ : Gorgias Press, 2007, p. 31-60. Sur Grègoras, voir R. Guilland, Essai sur Nicéphore Grégoras : l'homme et l'œuvre, P. : Paul Geuthner, 1926 ; T. Hart, « Nicephorus Gregoras, Historian of the Hesychast Controversy », Journal of Ecclesiastical History, 2 (2), 1951, p. 169-179 ; H.-V. Beyer, « Nikephoros Gregoras als Theologe und sein erstes Auftreten gegen die Hesychasten », Jahrbuch der Österreichischen Byzantinistik, 20, 1971, p. 171-188.

141. Sur lui, voir G.T. Dennis, « The Deposition of the Patriarch John Calecas », Jahrbuch der österreichischen byzantinischen Gesellschaft, 9, 1960, p. 51-56 (=Byzantium and the Franks 1350-1420. Collected Studies, Londres : Variorum, 1982).

142. Gouillard, « Le Synodikon », p. 86-87. Sur les frères Kydonès, voir G. Mercati, Notizie di Procoro e Demetrio Cidone, Manuele Caleca e Teodoro Meliteniota ed altri appunti per la 
Dosithéos connaissait fort bien ces affaires-là : il comptait faire imprimer une vraie bibliothèque d'écrits les concernant. Le Tó $\mu$ $\varsigma \dot{\alpha} \gamma \alpha \dot{\alpha} \pi \eta \varsigma$ abonde en textes de ce type. Le livre s'ouvre par une longue introduction de Dosithéos lui-même sur l'histoire de l'hérésie de Barlaam et de ses adeptes ${ }^{143}$, qui comprend aussi nombre de documents, entre autres ceux émis par Jean Cantacuzène ou pendant son règne : le rapport soumis par les évêques à l'impératrice Anne Paléologue (p. 7-8 ${ }^{144}$, le prostagma impérial pour la déposition de Jean Kalékas (p. 8-10) ${ }^{145}$, le tome hagiorite concernant la doctrine hésychaste (p. 34-39) ${ }^{146}$, le tome synodal condamnant l'hérésie de Barlaam (p. 40-51), celui condamnant l'hérésie de Barlaam et Akindynos (p. 52-85) et le tome synodal contre Prochoros Kydonès (p. 93-114) ${ }^{147}$, soit tous des personnages mentionnés dans la dédicace du livre de 1690. À cela s'ajoutent quinze écrits du patriarche Philothéos Kokkinos contre Nikèphoros Grègoras (p. 1-239) ${ }^{148}$.

Le projet de Dosithéos visait aussi l'édition d'autres écrits ayant trait à la controverse palamite ${ }^{149}$. Dans la liste de Posol'skij Prikaz, on trouve certaines œuvres antilatines par Barlaam de Calabre, dont celle sur la procession du Saint-Esprit, ouvrage très important, qui a inspiré toute une série de théologiens grecs, et même

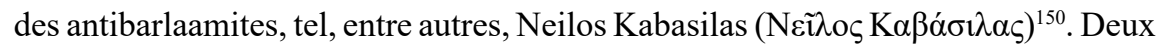

storia della teologia e della letteratura bizantina del secolo XIV, Vatican : Biblioteca Apostolica Vaticana, 1931, p. 359-403, et, plus récemment, J.R. Ryder, The Career and Writings of Demetrius Kydones. A Study of Fourteenth-Century Byzantine Politics, Religion and Society, Leyde - Boston : Brill, 2010.

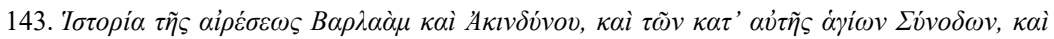

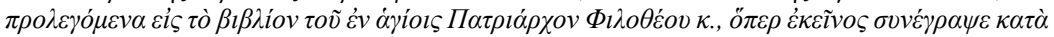

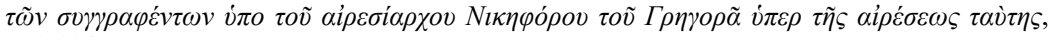
p. $1-114$.

144. $P G$ 151, 767-770 ; A. Rigo, « Il Rapporto dei metropoliti ad Anna Paleologa e altri eventi del $1346 »$, Byzantion, 85, 2015, p. 285-339.

145. $P G$ 151, col. 769-772, daté (par erreur) du 22 avril 1350. Cf. A. Rigo, « Il prostagma di Giovanni VI Cantacuzeno del marzo 1347 », Зборник Радова Византолошког Института, 50 (2), 2013, p. 741-762.

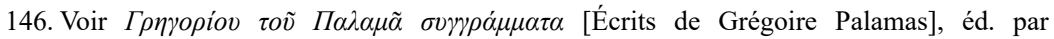

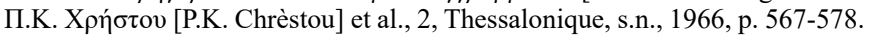

147. J. Darrouzès, Les regestes des actes du patriarcat de Constantinople, 1, Les actes des patriarches, Fascicule V, Les regestes de 1311 à 1376, P.: Institut français d'études byzantines,

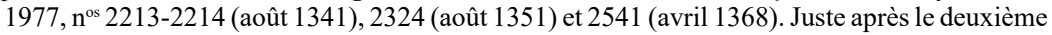
document, Dosithéos a inséré la Profession de foi de Palamas, cf. PG 151, 763-768 ; Г

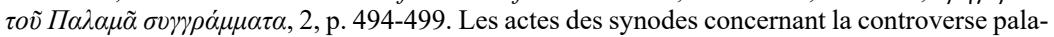
mite $(1341,1347$ et 1351) sont maintenant édités par F. Lauritzen in Melloni, éd., The Great Councils, p. 131-218. Dosithéos a publié ces documents pour répondre à Léon Allatius, qui s'est attaqué à la doctrine palamite, tout en ignorant les décisons synodales à ce sujet.

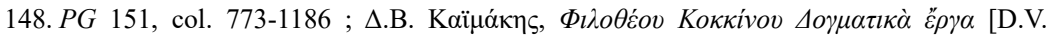
Kaïmakès, Philothéos Kokkinos. Euvres de dogmatique], Thessalonique : Kentro Vyzantinōn Ereunōn, 1, 1983.

149. Nous nous rapportons ici seulement aux ouvrages correspondant à l'époque de l'empereur Jean Cantacuzène.

150. Фонкич, « Иерусалимский патриарх », 55 ; Владимир, Систематическое описание, ms. 243, p. $321\left(\mathrm{n}^{\circ} 1\right)$ et ms. 250, p. 338 (n 40). Dans Tó 
écrits de Kabasilas y sont d'ailleurs présents ${ }^{151}$, ainsi qu'un ouvrage anonyme dirigé contre Dèmètrios Kydonès ${ }^{152}$. Dans son Tó $\mu о \varsigma \kappa \alpha \tau \alpha \lambda \lambda \alpha \gamma \tilde{\eta} \varsigma$ (Tome de la réconciliation), le patriarche a aussi édité une partie de l'écrit du canoniste Mathaios Blastarès $(\mathrm{M} \alpha \tau \theta \alpha$ ĩo $\zeta$ ó B $\lambda \alpha \sigma \tau \alpha \dot{\alpha} \rho\rceil \zeta)$ dirigé contre les Latins ${ }^{153}$.

La présence de Mathieu Cantacuzène dans le texte est en quelque sorte surprenante, vu qu'il n'a jamais régné comme empereur titulaire. Dosithéos ne se trompait pourtant pas car, après avoir été vaincu par Jean V Paléologue, Mathieu a effectivement passé quelque temps au Mont Athos et a rédigé les ouvrages mentionnés dans la dédicace de $1690^{154}$.

Il nous semble donc évident que ce texte est loin d'être seulement un éloge intéressé, dans le style propre aux panégyriques de cour, que Dosithéos aurait offert à Brâncoveanu, mais qu'il s'agit bien de la présentation publique d'un vaste projet théologico-politique. Dans le cadre de ce projet, la figure de Jean Cantacuzène était essentielle, car l'empereur-moine avait été un défenseur convaincu et efficace du

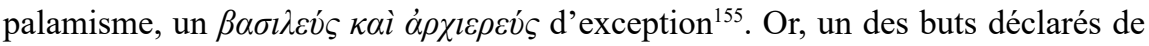
Dosithéos était précisément de répondre aux attaques des antipalamites modernes,

deux textes antilatins de Barlaam, mais sans en connaître l'auteur ( $n^{\circ} 13$, p. 367-378 et $n^{\circ} 14$, p. 378-387), A. Fyrigos, « Per l'identificazione di alcune opere 'ignoti auctoris' contenute nel Tó $\mu о \varsigma \alpha \dot{\alpha} \alpha \dot{\pi} \eta \varsigma$ di Dositeo, patriarca di Gerusalemme (e recupero di un opuscolo antilatino di Baarlam Calabro) », Rivista di Studi Bizantini e Neoellenici, 30-31, 1984-85, p. 171-190. Sur les œuvres antilatins de Barlaam, voir Idem, « La produzione letteraria antilatina di Barlaam Calabro », Orientalia Christiana Periodica, 45, 1979, p. 114-144 ; T.M. Kolbaba, « Barlaam the Calabrian : Three Treatises on Papal Primacy : Introduction, Edition, and Translation ", Revue des Études Byzantines, 53 (1), 1995, p. 41-115 ; Barlaam Calabro, Opere contro i Latini, éd. par A. Fyrigos, Vatican : Biblioteca Apostolica Vaticana, 1998.

151. Фонкич, « Иерусалимский патриарх », 52 et 54. Dans le premier cas, il s'agit du ms. 252, cf. Владимир, Систематическое описание, p. 346 ( $\left.\mathrm{n}^{\mathrm{o}} 18\right)$, respectivement du ms. 250, Ibidem, p. 342 ( $\mathrm{n}^{\circ}$ 100). Dans le second, il s'agit des mss. 242 et 250, Ibidem, p. 322 $\left(\mathrm{n}^{\circ}\right.$ 17) et p. $340\left(\mathrm{n}^{\circ} 71\right)$. Voir Nil Cabasilas, Sur le Saint-Esprit, introduction, texte critique, traduction et notes par le Hiéromoine Th. Kislas, P. : Cerf, 2001, p. 173-436. Sur Kabasilas, voir M.-H. Congourdeau, « Nil Cabasilas et les projets de concile œcuménique pour l'union des Églises », in M.-H. Blanchet, Fr. Gabriel, éds., Réduire le schisme? Ecclésiologies et politiques de l'Union entre Orient et Occident (XIII ${ }^{e}-X V I I^{e}$ siècles), P. : ACHCByz, 2013, p. 75-82.

152. Фонкич, « Иерусалимский патриарх », 57 ; Владимир, Систематическое описание, ms. 254, p. $348\left(\mathrm{n}^{\circ} 1\right)$.

153. Tó $\mu$ o $\kappa \alpha \tau \alpha \lambda \lambda \alpha \gamma \tilde{\eta} \varsigma$, Iași, 1694, p. 441-456. Voir K.A. Palaiologos, An Annotated Edition of the "Refutation of the Errors of the Latins » by Matthaios Blastares, thèse de doctorat inédite, université de Londres (Royal Holloway et Bedford New College), 2011 ; I. Polemis, « Notes on Two Texts Dealing with the Palamite Controversy », in S. Kotzabassi, G. Mavromatis, éds, Realia Byzantina, Berlin : De Gruyter, 2009, p. 207-212, ici p. 207-209. Dosithéos voulait aussi faire imprimer un autre écrit de Blastarès, Фонкич, « Иерусалимский патриарх », 61 ; Владимир, Систематическое описание, ms. 250, p. 339 (nº 61).

154. T. Teoteoi, « La querelle hésychaste reflétée dans les manuscrits grecs de la Bibliothèque de l'Académie Roumaine ", in Actes du XVI Congrès International des Études Byzantines, Bucarest, 1971, Bucarest: Academiei RSR, 1974, 2, p. 275-280 (=Byzantina et Daco-Romana, Bucarest : Omonia, 2008, p. 203-211, ici p. 204, n. 3). Dosithéos publie l'acte de confirmation

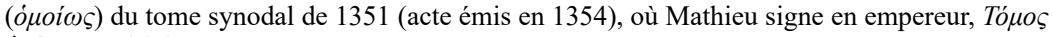
$\dot{\alpha} \gamma \dot{\alpha} \pi \eta \varsigma$, p. 84-85.

155. Le patriarche voulait d'ailleurs publier ses écrits contre Prochoros Kydonès, cf. Tó $\mu \circ \varsigma$ $\dot{\alpha} \gamma \alpha \dot{\pi} \eta \varsigma$, p. 1. 
qui proliféraient dans le monde catholique. Une première réponse avait déjà été donnée en 1690 même, par la publication de l'ouvrage de Maximos le Péloponnésien ${ }^{156}$. Le patriarche visait cependant beaucoup plus loin, ce qui apparaît très clairement à la lecture des prolégomènes à son Tó $\mu o \varsigma \dot{\alpha} \gamma \alpha \dot{\pi} \pi \eta \varsigma^{157}$, dans lesquels il explique sa démarche en s'attaquant au calomniateur moderne de Palamas et du patriarche Philothéos Kokkinos, le jésuite François Richard, auteur du Tó $\rho \gamma \alpha \tau \tilde{\eta} \varsigma$

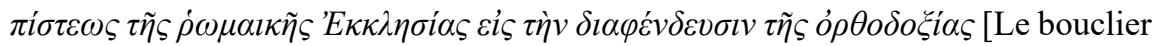
de l'Église romaine pour la défense de l'orthodoxie], 2 volumes, Paris, 1658) ${ }^{158}$. Léon Allatius, auteur de plusieurs ouvrages antipalamites et critique farouche, entre autres, du Triôdion grec et du Synodikon de l'Orthodoxie ${ }^{159}$, constitue une autre de ses cibles.

On comprend donc qu'en rappelant à Brâncoveanu les exploits de Jean Cantacuzène, Dosithéos ne faisait qu'utiliser leurs liens de parenté pour servir au mieux ses propres objectifs. L'empereur devait faire office de modèle pour son lointain descendant, qui était ainsi exhorté à s'élever à la hauteur des faits accomplis par son ancêtre ${ }^{160}$.

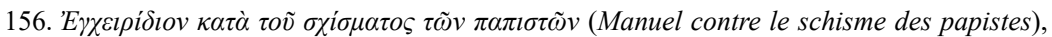
Bucarest, 1690 ; Legrand, Bibliographie... dix-septième siècle, 2, p. 475-478 ( $\left.\mathrm{n}^{\circ} 635\right)$; BRV, 1 , p. 297-298 (n $\left.{ }^{\circ} 89\right)$. L'offensive antilatine de Dosithéos avait commencé plus tôt, en Moldavie,

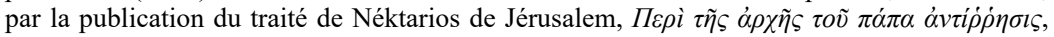
Iași, 1682 ; Legrand, Bibliographie... dix-septième siècle, 2, p. 401-408 ( ${ }^{\circ}$ 568) ; BRV, 1, p. 251-257 ( $\left.\mathrm{n}^{\circ} 75\right)$. Pour le contexte, voir Turdeanu, « Les controverses ». Pour les livres grecs imprimés en Moldavie, voir D. Simonescu, « Le monastère de Cetătzuia (Iassy) foyer de culture

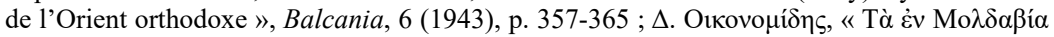

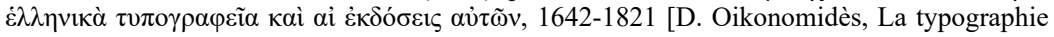

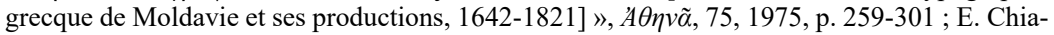
buru, Carte şi tipar în Ţara Moldovei [Livre et imprimerie en Moldavie], Iaşi : Universitatea «Al.I. Cuza », 2010, p. 317-344.

157. Texte écrit en 1697, en Valachie.

158. L'ouvrage, publié en grec vernaculaire, devait être diffusé à titre gracieux parmi les orthodoxes du Levant, mais nombre d'exemplaires ont été brûlés sur l'ordre du patriarche Parthé-

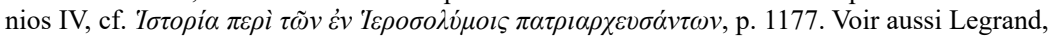

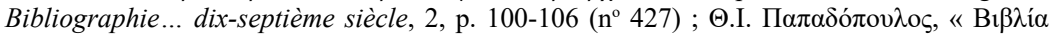

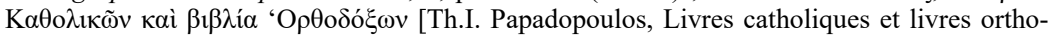

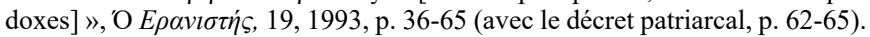

159. Dosithéos attaque à maintes reprises les Grecs ayant trahi l'orthodoxie et choisi le camp des « papistes ». Dans la préface à l'ouvrage de Maximos le Péloponnésien, il se réfère à

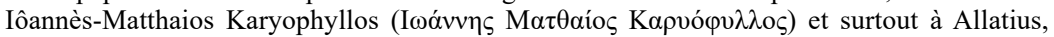
qui mourut, selon lui, en mordant et en avalant sa propre langue, châtiment divin pour les blasphèmes qu'il avait proférés à l'adresse de l'orthodoxie, Legrand, Bibliographie... dix-septième siècle, 2, p. 477 ; Palmieri, Dositeo, p. 84-85. Le Tó $\mu$ o $\kappa \alpha \tau \alpha \lambda \lambda \alpha \gamma \tilde{\eta} \varsigma$ s'ouvre par une longue introduction signée par le patriarche et dirigée précisément contre le livre d'Allatius, Enchiridion de Processione Spiritus Sancti, Rome, 1688 (I ${ }^{\mathrm{re}}$ édition 1658), Palmieri, Dositeo, p. 48-49.

160. Dosithéos venait ainsi à la rencontre des ambitions de Brâncoveanu lui-même, qui a toujours mis en exergue sa double ascendance illustre, R. Theodorescu, «Dunga cea mare a rodului și neamului său. Note istoriste în arta brâncovenească [" La grande lignée de sa famille ». Notes historiques dans l'art de l'époque de Brâncoveanu] ", in Cernovodeanu, Constantiniu, éds., Constantin Brâncoveanu, p. 180-202. 
Si tout cela est bien clair, il reste la question des Comnène : pourquoi eux ? Dosithéos s'explique : selon lui, le premier Cantacuzène connu, prénommé Jean, avait épousé la fille de Manuel Comnène, fils de Jean II et petit-fils d'Alexis I ${ }^{\text {er161 }}$. Pourtant, cela ne saurait suffire à faire état des Comnène parmi les ancêtres de Brâncoveanu. Il faut aussi observer que, seulement deux ans plus tôt, Dosithéos avait dédié un texte similaire au prince Șerban Cantacuzino, le patron de la traduction en roumain de la Bible (Bucarest, 1688) ${ }^{162}$. Il n'y manquait pas l'occasion de louer les ancêtres Cantacuzène du prince, notamment Jean VI, habile diplomate et homme d'État, mais également théologien exquis et athlète de la vraie foi, vainqueur du faux prophète, défenseur et promoteur de l'orthodoxie dans le monde. Il passait ensuite aux Cantacuzène récents, rappelant le fameux épisode de la confiscation des églises chrétiennes au temps du sultan Soliman et le rôle de Dèmètrios Kantakouzènos dans cette affaire ${ }^{163}$, puis terminait par le père du prince, le feu chambellan Constantin. Cependant, il ne faisait aucunement mention des empereurs Comnène, pas plus que de leurs exploits ou de leur qualité de «monarques et archiéreis $»^{164}$.

Pourquoi Dosithéos a-t-il changé de discours dans la dédicace de 1690 ?

Comme l'ont établi les savants modernes, l'ère des Comnène fut marquée par de fortes controverses théologiques, surtout dans les rapports avec la papauté ${ }^{165}$. C'est à cette époque que la question du Filioque reprit de l'importance dans le monde byzantin, en relation avec celle de la primauté du Pape, alors qu'auparavant le Filioque n'occupait qu'un rôle assez marginal par rapport au problème,

161. Le patriarche se fonde ici sur l'œuvre de Choniatès, mais il confond certains détails, car ce Jean Cantacuzène fut marié avec Marie, la fille du frère de l'empereur Manuel, le sébastokrator Andronikos, cf. D.M. Nicol, The Byzantine Family of Kantakouzenos (Cantacuzenus) ca. 1100-1460: A Genealogical and Prosopographical Study, Washington, DC : Dumbarton Oaks, Center for Byzantine Studies, 1968, p. 4. Dosithéos s'adressait à un connaisseur, vu que Brâncoveanu possédait pratiquement tous les ouvrages d'histoire byzantine ayant trait à la période Comnène (Choniatès, Anne Comnène, etc), ainsi que l'œuvre historique de Jean Cantacuzène, tous publiés à Paris dans la collection Corpus Byzantinae Historiae, dirigée par Charles du Cange de Fresne, M. Caratașu, C. Dima-Drăgan, « Les ouvrages d'histoire byzantine de la bibliothèque du prince Constantin Brancovan », Revue des Études Sud-Est Européennes, 5 (3-4), 1967, p. 435-447.

162. $B R V, 1$, p. 286-290, le texte est en roumain.

163. G. Veinstein, « Les conditions de la prise de Constantinople en 1453 : un sujet d'intérêt commun pour le patriarche et le grand mufti », in Le Patriarcat oecuménique de Constantinople aux XIV $-X V I^{e}$ siècles : rupture et continuité. Actes du Colloque international, Rome 5-7 décembre 2005, P. : De Boccard, 2007, p. 275-289.

164. Brâncoveanu avait repris à son compte la stratégie de légitimation mise en œuvre par son oncle maternel et prédécesseur, Șerban Cantacuzino, D. Ionescu, «Șerban Cantacuzène et la restauration byzantine. Un idéal à travers ses images », in E. Stănescu, N.-Ș. Tanașoca, éds., Études byzantines et post-byzantines, 1, Bucarest : Academiei RSR, 1979, p. 239-269. Cependant, ni les panégyristes de ce prince ni lui-même n'ont jamais fait référence aux relations de parenté avec les Comnène.

165. J.M. Hussey, The Orthodox Church in the Byzantine Empire, Oxford : Clarendon Press, 1986, p. 168. 
beaucoup plus débattu, des azymes ${ }^{166}$. Dans cette histoire, le règne de Manuel Comnène constitue un tournant, ce qui explique l'attention que Dosithéos lui accorde dans sa préface-dédicace. Toutes ces questions étaient d'une actualité accrue et le patriarche préparait depuis longtemps son attaque ${ }^{167}$. Les ouvrages qu'il a fait publier ou bien ceux qu'il a voulu voir imprimés sont en grande majorité centrés sur ces questions-là : les azymes, le Filioque et la primauté du pape ${ }^{168}$. L'époque des Comnène n'était donc pas si éloignée que cela; tout au contraire, elle devait fournir des armes pour mener le combat. La menace représentée par le prosélytisme catholique parmi les orthodoxes de Pologne et de Transylvanie et l'activité des polémistes catholiques ont obligé Dosithéos à passer à l'acte. Une fois de plus,

166. T.M. Kolbaba, «Byzantine Perceptions of Latin Religious "Errors" : Themes and Changes from 850 to 1350 », in A.E. Laiou, R.P. Mottahedeh, éds., The Crusades from the Perspective of Byzantium and the Muslim World, Washington, DC : Dumbarton Oaks Research Library and Collection, 2001, p. 117-143 ; A. Bucossi, « Dibattiti teologici alla corte di Manuele Comneno ", in A. Rigo et al., éds., Vie per Bisanzio. VIII Congresso dell'Associazione Italiana di Studi Bizantini, Venezia, 25-28 novembre 2009, Bari : Edizioni di Pagina, 2012, 1, p. 311-321. Sur la controverse des azymes, voir J. H. Erickson, « Leavened and Unleavened : Some Theological Implications of the Schism of 1054 », St. Vladimir's Theological Quarterly, 14 (3), (1970, p. 155-176 ; M.H. Smith III, And Taking Bread ... Cerularius and the Azyme Controversy of 1054, P. : Beauchesne, 1978. Sur le Filioque, voir A.E. Siecienski, The Filioque : History of a Doctrinal Controversy, New York : Oxford University Press, 2010. Sur la primauté romaine, voir K1. Schatz, Der päpstliche Primat : seine Geschichte von den Ursprüngen bis zur Gegenwart, Würzburg : Echter, 1990 [version française : La primauté du Pape : son histoire des origines à nos jours, traduction de l'allemand par J. Hoffmann, P. : Cerf, 1992].

167. B. Fonkič a établi que Dosithéos avait soigneusement préparé sa campagne d'édition en faisant faire des copies d'après des manuscrits anciens, Фонкич, « Иерусалимский патриарх ». Une partie des originaux avait appartenu au grand drogman de la Porte, Panagiotès Nikousios, qui les avait récupérés de la bibliothèque de l'érudit crétois Maximos Margounios

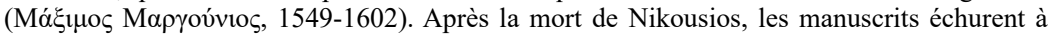
Dosithéos (1674), Ibidem, p. 278-279 ; Б.Л. Фонкич, « Материалы для изучения библиотеки Максима Маргуния [Documents pour l'étude de la bibliothèque de Maximos Margounios] », Византийский Временник, 38, 1977, p. 141-153. Le projet de Dosithéos était donc né durant les dernières années de vie de Nikousios. Le patriarche comptait le continuer par la publication d'une nouvelle anthologie de textes antilatins : Tó $\mu$ os eipeveí [Tome de la paix]; voir sa

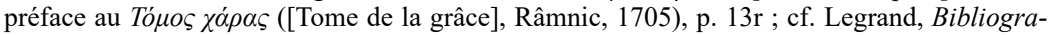
phie... dix-huitième siècle, 1, p. 45.

168. Nombre d'auteurs cités dans la dédicace de 1690 sont aussi mobilisés dans son Manuel, publié dans le même livre : Nikètas Seidès (p. 60, sur les azymes), Neilos Kabasilas, Nikolaos de Méthone (p. 49 et 65, discours contre Panteugènos ; p. 52, 56, 66, 68 et 72, sur les azymes), le patriarche Jean Chrysostomitès (p. 66, 68, 74, sur les azymes), Jean V d'Antioche (p. 45, sur les azymes) ; Théodore Smyrnaios (p. 72), Théophylaktos de Bulgarie (p. 67, 69, 73), etc. Les controverses de l'époque Comnène sont passées en revue dans le même ouvrage (voir, par exemple, p. 47 et suiv. et p. 57), en sorte que la dédicace communique parfaitement avec le

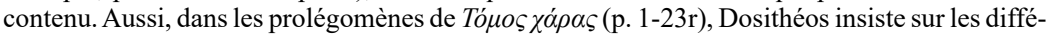
rences majeures entre le dogme romain et le grec : la procession du Saint-Esprit et la primauté du pape, et répond ainsi au cardinal Kollonitch (p. 2r-2v). Voir aussi Palmieri, Dositeo, p. 66-68. En général, voir Barbu, Purgatoriul, p. 324-326 (azymes), 326-338 (purgatoire), 350-379 (primauté du pape), 338-344 (Filioque). Voir aussi I. Kyriakantonakis, « Between Dispute and Erudition. Conflicting Readings of Byzantine History in Early Modern Greek Historical Literature », in O. Delouis, A. Couderc, P. Guran, éds., Héritages de Byzance en Europe du Sud-Est à l'époque moderne et contemporaine, Athènes : École Française d'Athènes, 2013, p. 161-178, surtout p. 173-177. 
lorsqu'il évoque les ancêtres illustres de Brâncoveanu, le patriarche lui propose un modèle à suivre, en étroite relation avec ses propres priorités.

Le contexte immédiat a joué pour Dosithéos. Un an seulement après sa prise de pouvoir, le prince valaque s'est confronté à une invasion des troupes habsbourgeoises qui ont occupé la capitale, le forçant à solliciter l'aide de la puissance suzeraine, la Porte ottomane. L'occupation autrichienne n'a pas duré longtemps : en janvier 1690, les impériaux ont dû se retirer sous la pression des armées turco-tatares ${ }^{169}$. Le mal était pourtant fait : il était évident dès lors que la grande puissance catholique voisine ne menaçait pas seulement les consciences, mais aussi les biens et les vies des orthodoxes. Dosithéos a réagi immédiatement et a fait imprimer le traité de Maximos le Péloponnésien contre « le schisme des papistes ». Quelques mois plus tard, il a récidivé en publiant l'ouvrage anticalviniste évoqué plus haut : ses deux cibles majeures étaient ainsi atteintes. Même si Brâncoveanu ne se trouvait pas à Bucarest à ce moment-là ${ }^{170}$, il est certain que les deux livres ont été publiés avec son consentement et sous son patronage, en réaction à l'agression autrichienne ${ }^{171}$. L'argument de la foi faisait donc figure d'arme politique, de la même manière que le politique influait, et considérablement, sur les questions confessionnelles.

Il semble donc très probable que Dosithéos a vu dans les événements de 1690 l'occasion parfaite pour déclencher l'offensive anticatholique et antiprotestante qu'il préparait de longue date. C'est pourquoi il ne lésine pas sur les moyens pour convaincre le prince valaque de s'y engager pleinement. En évoquant la gloire des ancêtres, le patriarche réclame en fait un investissement sur mesure de la part du rejeton, auquel reviennent le droit et l'obligation d'offrir aux fidèles orthodoxes des ouvrages qui s'attaquent aux hérésies du siècle présent. Quant à lui-même, il se veut la cheville ouvrière de ce noble projet, l'intermédiaire entre le Christ et l'Église, d'une part, et le monarque, de l'autre. Il est le sage et le saint, celui qui fournit des conseils et prie Dieu pour que le nom du prince soit loué dans ce siècle, avec ceux des pieux empereurs et princes et des athlètes de la foi, et dans l'avenir, qu'il se retrouve dans l'assemblée des premiers-nés de l'Église, dont les noms sont glorifiés éternellement dans les cieux. L'exemple des ancêtres revient constamment et l'argument ultime renvoie directement au Synodikon de l'Orthodoxie :

$\mathrm{Vu}$ les faits accomplis par les cinq empereurs tes ancêtres maternels, ce ne fut pas sans raison qu'ils ont été appelés rois et archiéreis. C'est pourquoi les cinq sont béatifiés par le Synodikon de l'Orthodoxie ensemble avec les autres empereurs leurs pairs.

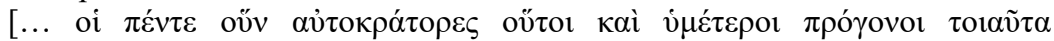

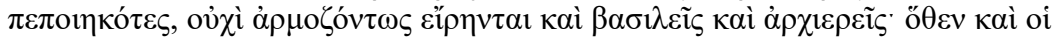

169. Binder, « Cronologia campaniei din $1690 »$.

170. Il se trouvait en Transylvanie, en campagne contre les Autrichiens, Ibidem.

171. Vasiliu, « Constantin Brâncoveanu », p. 121. 


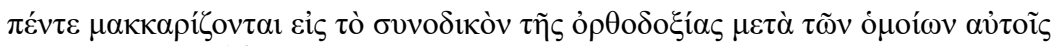

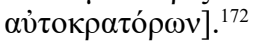

Autrement dit, Dosithéos trace ici un vrai programme d'action à mettre en œuvre par le prince valaque et lui fait comprendre que les hauts faits qu'il doit accomplir peuvent lui assurer une place dans le Synodikon de l'Orthodoxie, comme ce fut jadis le cas de ses ancêtres ${ }^{173}$ !

\section{En guise de conclusion}

$\mathrm{Au}$ vu de ces faits, on saisit mieux l'enjeu de la publication du Synodikon de l'Orthodoxie en langue roumaine sous le patronage de Constantin Brâncoveanu. Bien que Dosithéos n'ait pas toujours réussi à mobiliser le prince dans la direction qu'il aurait lui-même souhaitée, une collaboration a effectivement existé entre eux deux. S'il est sans doute exagéré de parler d'une « croisade contre les Latins » en Valachie ${ }^{174}$, il est certainement légitime d'y voir la scène d'un âpre combat pour la défense de l'orthodoxie et, sur ce plan, les deux protagonistes visaient souvent des objectifs similaires. En même temps, les ambitions du prince valaque de faire figure de protecteur de l'orthodoxie « captive », ambitions soutenues par une politique concrète et cohérente, nous permettent de supposer qu'il ne fut pas insensible à l'honneur que le patriarche de Jérusalem lui avait (indirectement) proposé.

Dans ce contexte, le Synodikon s'avérait un texte nécessaire, même s'il ne semble pas avoir été investi de la portée polémique que détenaient d'autres écrits de l'époque. Patronnée par le métropolite valaque Teodosie et réalisée par l'ex-évêque de Huși Mitrofan, la publication de la version roumaine de ce document est liée tant à la politique religieuse de Brâncoveanu, une politique plutôt défensive, mais ferme, comme l'on a vu, qu'à l'offensive antilatine et anticalviniste menée par le

172. En effet, tous ceux nommés par Dosithéos, Mathieu Cantacuzène excepté, figurent dans le Synodikon parmi les empereurs pieux de sainte mémoire, cf. Gouillard, "Le Synodikon », p. 94-95 et 98-99.

173. Dosithéos travaillait, pour ainsi dire, le Synodikon sur la table. Dans sa Confession de foi insérée dans le Manuel de 1690, il cite les anathèmes contre Vassilios le Bogomile et contre Sotèrichos Panteugenos et ses adeptes, tous extraits du Synodikon, Kontouma, « La Confession de Foi », p. 349, 361. De même, dans son ouvrage contre Iôannès Karyophyllès

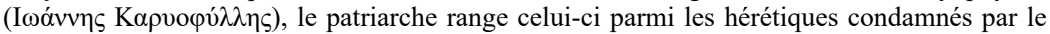
Synodikon, auxquels il ajoute les ennemis plus récents de la foi orthodoxe : Bérenger, Calvin,

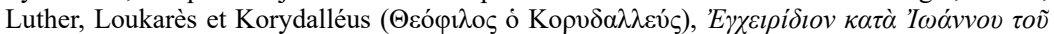

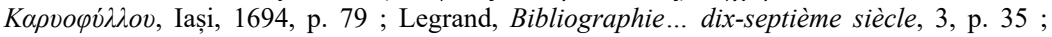
Miladinova, Panoplia Dogmatike, p. 116. Selon cette auteure, le passage décrivant l'interrogatoire de Karyophyllès lors du synode convoqué par Dosithéos en 1691 renvoie directement à l'interrogatoire de Vassilios le Bogomile par Alexis I ${ }^{\mathrm{er}}$ Comnène, Ibidem, p. 117.

174. L'échange de lettres entre Kollonitch et le métropolite Teodosie fit croire Nikolaos Papadopoulos Komnènos qu'en Valachie « si grida alla crociata contro i Latini », Vasiliu, « Constantin Brâncoveanu », p. 115 (le 10 novembre 1702). 
patriarche de Jérusalem. Le moment était venu que ce véritable lieu de mémoire de l'orthodoxie soit rendu accessible à tous les fidèles de langue roumaine, afin qu'ils comprennent une fois pour toutes que la vie éternelle est une récompense réservée exclusivement à ceux qui observent scrupuleusement la Tradition, telle qu'elle a été établie par les Pères et confirmée par les synodes. Tout égarement était fatal, toute

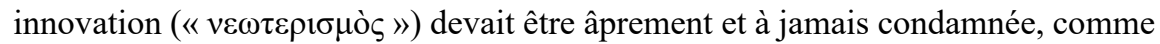
l'avaient fait par le passé les archiéreis et les empereurs de pieuse mémoire. Le Synodikon était là pour rappeler constamment leur exemple.

ivan.biliarsky@gmail.com

Académie bulgare des Sciences, Institut d'Histoire, Sofia

paunradug@gmail.com

Centre d'Études des mondes russe, caucasien et centre-européen

CNRS-EHESS, Paris 